\title{
Microstructural Evolution and Hardness of Rapidly Solidified Hypereutectic Al-Si Surface Layers Produced by Laser Remelting
}

Jaafar Abboud ( $\sim$ jalmayya@umich.edu )

University of Babylon

Metin Kayitmazbatir

University of Michigan

Amit Misra

University of Michigan

Jyoti Mazumder

University of Michigan

\section{Research Article}

Keywords: Hypereutectic Al-Si, laser rapid solidification, microstructure, nanoindentation

Posted Date: April 13th, 2021

DOI: https://doi.org/10.21203/rs.3.rs-402623/v1

License: (c) (i) This work is licensed under a Creative Commons Attribution 4.0 International License. Read Full License

Version of Record: A version of this preprint was published at Advances in Materials and Processing Technologies on February 14th, 2022. See the published version at https://doi.org/10.1080/2374068X.2022.2037352. 


\title{
Microstructural Evolution and Hardness of Rapidly Solidified Hypereutectic
}

\section{Al-Si Surface Layers Produced by Laser Remelting}

\author{
J.H. Abboud* ${ }^{1}$, M. Kayitmazbatir ${ }^{2}$, A. Misra ${ }^{2,3}$, J. Mazumder ${ }^{2}$ \\ ${ }^{1}$ Department of Automotive, College of Engineering / Al-Musaib, University of Babylon, Hilla, Iraq. \\ ${ }^{2}$ Department of Mechanical Engineering, University of Michigan, Ann Arbor, MI 48109-2136, USA \\ ${ }^{3}$ Department of Materials Science and Engineering, College of Engineering, University of Michigan, Ann \\ Arbor, MI 48109-2136, USA
}

Keywords: Hypereutectic Al-Si, laser rapid solidification, microstructure, nanoindentation.

\section{Abstract}

A laser rapid solidification technique was employed to remelt and refine the microstructure of Al-25wt.\%Si and Al-30wt.\%Si alloyed layers produced by laser melting. The microstructure of the as-fabricated Al-Si layers consisted of irregular polygonal primary Si crystals of size 5 to $7 \mu \mathrm{m}$, fine $\alpha-\mathrm{Al}$ dendrites, and $\mathrm{Al}-\mathrm{Si}$ eutectic. Laser rapid remelting results showed a significant refinement of all the solidified phases with increasing scan speed and decreasing laser power. At the lowest laser power $(800 \mathrm{~W})$, the sizes of the primary Si crystals were reduced to a sub-micron level and an interwoven network of nano-sized eutectic colonies was obtained. The higher cooling rates, resulted in a reduction in the amount of the $\alpha$-Al phase especially those surrounding the primary $\mathrm{Si}$, thereby stimulating the eutectic Si fibers to grow from the pre-existing primary $\mathrm{Si}$ crystals and increased the proportion of the fibrous eutectic. Transmission electron microscopy revealed fibrous eutectic, which was internally nano-twinned, with a diameter approaching as low as 10-15 nm for the highest cooling rate. The hardness measured by nanoindentation of the eutectic in the remelted Al-25wt.\%Si layer increased with decreasing the eutectic spacing $(\Lambda)$ reaching a maximum value of $3.15 \mathrm{GPa}$.

\section{Introduction}

The use of high silicon Al-Si alloys in the automobile industry has been constantly increasing due to the multiple advantages that result from adding silicon, the most important of which is the increase in wear resistance and thermal conductivity [1,2]. However, when the silicon content exceeds $20 \mathrm{wt} \%$, the alloys suffer from a deterioration of other mechanical properties due to the formation of massive and angular silicon particles with sharp edges, which act as crack initiation sites and significantly reduces the fatigue life. Therefore, to meet the growing demands in automotive, transport, aerospace, marine, aeronautical, and missile technology; the size and morphology of the silicon phase must be refined and modified as the finer primary silicon crystals generally result in improved mechanical properties, such as toughness and ductility. Refinement can be achieved by controlling the nucleation and growth of the silicon phase via different chemical [3-18], mechanical [19-22], and thermal methods [23-25]. The chemical modification involves the addition of some modifier elements, in trace levels like $\mathrm{Na}$ [3-5], Sr [6], and rare earth elements [7]. This approach proved to be very effective and economical in the refinement and modification of the eutectic silicon 
but less effective for the refinement of the large primary silicon. For the refinement of the silicon in the hypereutectic region, it is reported that the addition of phosphorus in the form of $\mathrm{Al}-\mathrm{P}$ or $\mathrm{Cu}-\mathrm{P}$ is effective due to the formation of AlP particles, which act as nucleation agents of the primary silicon [8,9]. A recent investigation found that cerium has an effective role in reducing the size of the primary silicon from 94 to 33 $\mu \mathrm{m}$ in Al-18wt.\%Si alloy and improving mechanical properties $[10,18]$. On the other side, the addition of rare earth such as $\mathrm{Nd}$ [11], La [12], and Er [13], showed a slight effect on the refinement of the primary silicon size. However, a combination of $\mathrm{P}+\mathrm{Sr}$ [15], $\mathrm{Sb}+\mathrm{Sr}$ [16], Ti and/or Sr [17], and $\mathrm{Sr}+\mathrm{Ce}$ [18] were proven to be effective to some extent in improving the strength and ductility but the size of the primary silicon crystals did not reach the nanoscale [10]. Also, some of the chemical refinement agents suffer from losses, evaporation, and oxidation during services, besides, the tendency toward gas pick-up leading to the formation of porosity. Macrosegregation of the silicon phase is another defect associated with the conventional casting of Al-Si alloys and one suggestion to overcome this defect is to create a strong stirring and vibration that could disperse these gathered particles and improve the uniformity [19-22]. However, this technique has many complexities as well as stirring can lead to increase porosity. Jie et al. [21] demonstrated that although an intense rotating magnetic field (RMF) technique was employed, the Si agglomeration phenomenon was still present as the solidification rate was slow, which implies that the formation and distribution of the Si phase in hypereutectic Al-Si alloys are dependent on many factors.

Thermal methods, which include melt spinning [23], superheating [24], powder atomization [25], and laser melting [26-30] are other effective approaches used for the refinement of the Si phase. The high cooling rates, which may reach $10^{5}$ to $10^{7} \mathrm{C} / \mathrm{s}$ play a large role in the size of the critical nuclei, and subsequently, the effective number of nuclei that will ultimately produce fine-grained structures. As the cooling rate increases, the diffusion of silicon atoms becomes more difficult, and this leads to a reduction of the final size. Jiang et al [23] have reported that the size of the primary silicon could reach as small as $2-5 \mu \mathrm{m}$ with a very fine fibrous eutectic. In a powder atomization technique [25], a characterization of hypereutectic Al-50wt.\%Si powder alloys ( $25 \mu \mathrm{m}$ diameter) solidified under the far-from-equilibrium condition showed primary silicon sizes ranged from 2 to $5 \mu \mathrm{m}$ embedded in a eutectic structure which is similar to that obtained by laser melting of a similar alloy composition [27].

From the above-mentioned researches, it appears that in high-silicon Al-Si alloys, it is very difficult to refine the silicon crystals particularly the primary silicon to nano-sized due to the large solidification range of these alloys, which increases with the increasing silicon content. The present investigation is an attempt to use the laser melting technique for two purposes. First, to produce high silicon hypereutectic Al-Si alloyed layers. The second is to use the laser remelting technique at a fast scan speed with relatively low power levels to refine the silicon phase to a nano-sized. Another objective is to study the influence of decreasing the size and spacing of the eutectic on the nanoindentation hardness. The longer-term objective of this work is to develop a high-volume fraction of nano-sized silicon crystals on the surface of the aluminum which could lead to improved wear resistance. 


\section{Materials and Sample Preparation}

\section{Preparation of the Al-Si layer}

A commercial purity aluminum (CP Al) plate of $50 \mathrm{~mm}$ long x 25mm wide x $6 \mathrm{~mm}$ thick, and silicon powder, of 325 mesh, and $99.9 \%$ purity (ALDRICH Chemistry) have been used to prepare the alloyed layers. Several slots of depths 0.3 and 0.35 , were prepared along the length of the aluminum plate by a machining process. Silicon powder was inserted and compacted in the grooved aluminum plate until the slot gap is filled and the extra powder was removed. Great care was taken to ensure the uniformity of the silicon powder distribution in the designated spaces before the laser treatment. This method was chosen due to the difficulty of feeding the silicon powder into the feeder, as well as powder jam, which hinders its regular flow.

\section{Fabrication and remelting of the Al-Si tracklayer}

A solid-state Nd-YAG (HLD 4002) disk laser operated at 600-2000W with a $2 \mathrm{~mm}$ beam diameter was used for producing the Al-Si alloyed track layers and for the overlapping remelting treatments. The Al-Si alloyed layers were prepared by irradiating the laser beam onto the surface of a commercial purity Al substrate, which contains silicon powder to a specific depth. In this experiment, the laser head was stationary while the Al substrate was moving. The relative movement between the Al substrate and the stationary laser head was controlled by a computerized $\mathrm{X}-\mathrm{Y}-\mathrm{Z}$ table moving in three perpendicular directions. The movement in $\mathrm{X}$ direction was used to control the scanning speed while in $\mathrm{Z}$ direction is used to change the laser beam diameter. The first experiment was designed to fabricate the Al-Si tracklayers of $40 \mathrm{~mm}$ length using laser power of $2000 \mathrm{~W}$ and at a scanning speed of $10 \mathrm{~mm} / \mathrm{s}$, followed by a remelting process at a constant traverse speed of $180 \mathrm{~mm} / \mathrm{s}$ and different laser powers $(1000,800$, and 600W). Two tracklayers, $1 \mathrm{~A}$ (two remelts) and 2A (four remelts) were selected for study and analysis. Table1 illustrates the various processing parameters used in the fabrication and remelting treatments of the tracklayers $1 \mathrm{~A}$ and $2 \mathrm{~A}$. Before performing any remelting experiments, the top surface of the alloyed track was ground, polished, cleaned, and slightly etched. The processes of melting and remelting were conducted within an inert controlled atmosphere to avoid oxidation during melting and solidification.

Table 1. Processing parameters used in the alloy fabrication and remelting treatments.

\begin{tabular}{|l|l|c|c|c|l|}
\hline $\begin{array}{l}\text { Tracklayer } \\
\text { no. }\end{array}$ & Laser treatment & $\begin{array}{c}\text { Power } \\
\mathrm{W}\end{array}$ & $\begin{array}{c}\text { Speed } \\
\mathrm{mm} / \mathrm{s}\end{array}$ & $\begin{array}{c}\text { Beam diameter } \\
\mathrm{mm}\end{array}$ & $\begin{array}{c}\text { Si-powder } \\
\text { thickness, mm }\end{array}$ \\
\hline $1 \mathrm{~A}$ & Fabrication & 2000 & 10 & 2 & 0.3 \\
& Remelting & 2000 & 180 & 2 & ---- \\
& Remelting & 1000 & 180 & 2 & ---- \\
\hline $2 \mathrm{~A}$ & Fabrication & 2000 & 10 & 2 & 0.35 \\
& Remelting & 2000 & 180 & 2 & ---- \\
& Remelting & 1000 & 180 & 2 & ---- \\
& Remelting & 800 & 180 & 2 & ---- \\
& Remelting & 600 & 180 & 2 & - \\
& & & & & \\
\hline
\end{tabular}




\section{Microstructure characterization}

After the first laser melting and remelting experiments were done, transverse sections were cut, cold mounted, ground on 400, 600, 1200, and 2000 grit $\mathrm{SiC}$ paper then polished with a $3 \mu \mathrm{m}$ and fine polished with $0.3 \mu \mathrm{m}$. The samples were cleaned and etched with Keller's reagent (containing $95 \mathrm{ml}$ of $\mathrm{H}_{2} \mathrm{O}, 2.5 \mathrm{ml}$ of $\mathrm{HNO}_{3}, 1.5$ $\mathrm{ml}$ of $\mathrm{HCl}$, and $1.0 \mathrm{ml}$ of $\mathrm{HF}$ ) for $3 \mathrm{~s}$, rinsed with water, and then dried. The composition and the microstructure of the alloyed zones were examined by scanning electron microscopy (TESCAN MIRA3 FEG SEM) equipped with an energy dispersive spectrometry (EDS) detector and transmission electron microscopy (JEOL 2010F AEM). Thin foils were prepared by cutting a slice of $0.3 \mathrm{~mm}$ thick parallel to the laser scanning and further ground to $100 \mu \mathrm{m}$. A punching tool was used to obtain a $3 \mathrm{~mm}$ diameter foil. The sample was mechanically polished and finally thinned by a Gatan Precision Ion Polishing System (Gatan PIPS ${ }^{\mathrm{TM}}$ ) where low-angle and low-current polishing conditions were used in conjunction with a liquid nitrogen cold stage. The electron microscopy and nanoindentation experiments were conducted at a Michigan Center for Materials Characterization at the University of Michigan.

\section{Nanoindentation hardness}

The nanoindentation hardness and elastic modulus of the eutectic region of tracklayer A-1, which exhibited different spacing, were measured at different locations. The indentation hardness experiment was carried out at room temperature employing a Bruker TI-950 Triboindenter equipped with a diamond tip of a three-sided Berkovich probe. The indenter was employed to measure with a peak load of $1 \mathrm{mN}$ and a quasistatic trapezoidal loading function ( $5 \mathrm{~s}$ load and $2 \mathrm{~s}$ unload hold time) and indentation depth of $200 \mathrm{~nm}$. The reported data is an average of at least three indents in each zone. Measurements were carried out on the transverse section, which was mechanically polished to $0.3 \mu \mathrm{m}$ finished, and clean with ethanol.

\section{Results}

\section{General shape and dimension of tracklayer $1 \mathrm{~A}$.}

Fig.1a shows a typical transverse section of the laser fabricated Al-Si alloyed layer (tracklayer-1A), which is processed at a power (P) $2000 \mathrm{~W}$, a beam diameter (bd) $2 \mathrm{~mm}$, and scanning speed ( $\mathrm{v}$ ) $10 \mathrm{~mm} / \mathrm{s}$. After the completion of the first melt to synthesize the alloy, it was remelted twice at a traverse speed of $180 \mathrm{~mm} / \mathrm{s}$ and laser powers $2000 \mathrm{~W}$ and $1000 \mathrm{~W}$, respectively. The alloyed zone had a conduction limited shape of a total depth of $0.55 \mathrm{~mm}$ and a width of $1.4 \mathrm{~mm}$ (Fig.1a). It is apparent from the figure that all the silicon powder has melted and dissolved in the molten aluminum forming a homogeneous alloy with a fine structure (Fig.1a, zone 1) while the second and third zones showed a more homogeneous and much finer structure due to the remelting process. The depths of the remelted zones were 250 and $120 \mu \mathrm{m}$ at powers of $2000 \mathrm{~W}$ and $1000 \mathrm{~W}$, respectively. Fig.1a also showed a narrow dendritic region at the interface between the base metal and zone 1 , which are interpreted as $\alpha$-Al dendrites. Also, the interfaces between zone 1 and zone 2 and 3 showed an agglomeration of fine silicon particles that coexisted with near eutectic and hypoeutectic structures. The upper part of the third melted zone showed the influence of the convectional fluid flow, which led to the formation of Si-rich and Si-poor zones and pushed the silicon particles toward the top and the edges of the melted zone. It is important to mention here that segregation and clustering of the silicon crystals are very common in a 
conventional cast and even the rapidly cooled hypereutectic Al-Si alloys due to the lower density of the Si particles and the strong convectional fluid flow, which arises from the temperature gradient and other solidification parameters [25]. Fig.1 b illustrates the decrease of the remelted depth with decreasing laser power (or reducing the heat input), which is equal to the $(\mathrm{P} / \mathrm{v}, \mathrm{J} / \mathrm{mm})$. As the heat input reduces, the depth decreases, and thus the cooling rate increases. Fig.1b showed that the melted depth decreased linearly with the decrease of the heat input and when the heat input is reduced to a minimum value $(5.55 \mathrm{~J} / \mathrm{mm})$, the depth decreases rapidly reaching $120 \mu \mathrm{m}$. Due to the significant decrease in the depth of the third zone, it is expected that the cooling rate will be the highest compared to the first and second zones and will display the finest structure.
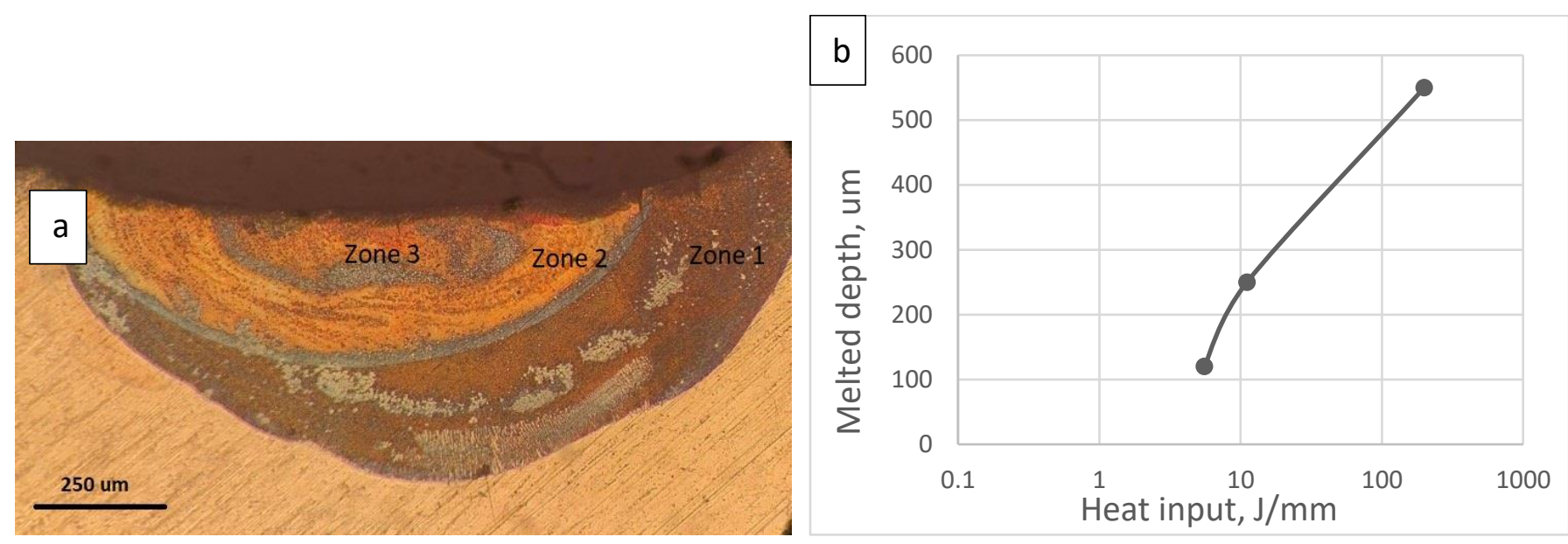

Fig.1: (a) Cross-section of the laser fabricated Al-Si alloyed layer (tracklayer 1A) and laser remelted at different heat inputs, (b) variation of the remelted depth with the heat input.

\section{Composition analysis}

EDS analysis was performed at different locations at different zones in the Al-Si alloyed layer and was found that the silicon content in the lower part, where the microstructure exhibited a dendritic structure, was slightly lower than that in the other part of the alloyed layer (see Fig.1a). The silicon content near the interface was 17.6wt. \%Si while it was $20 \mathrm{wt} \% \mathrm{Si}$ in the eutectic region excluding the Si particles and 24wt.\%Si in the region which showed clustering of Si crystal and the matrix (Fig.2a). Similar values were obtained in zone 2 and 3 (Fig. $2 \mathrm{~b}$ and $\mathrm{c}$ ). The average composition of the alloyed layer was found to be $25 \mathrm{wt} . \% \mathrm{Si}$. The results of the EDS analysis of the eutectic region showed an increase in the silicon content of the eutectic concentration to 20wt.\%Si in zone 1 and 22wt.\%Si in zone 2 and 24wt.\% in zone 3 (Fig.2c). These values are much higher than those reported in the Al-Si diagram (12.6wt.\%Si). This indicates that as the melted depth became smaller, the cooling rate increased, pushing the eutectic point toward a higher silicon content as reported in an earlier study on Al-20wt.\%Si and [27] and Al-16wt.\%Si alloy [29]. 

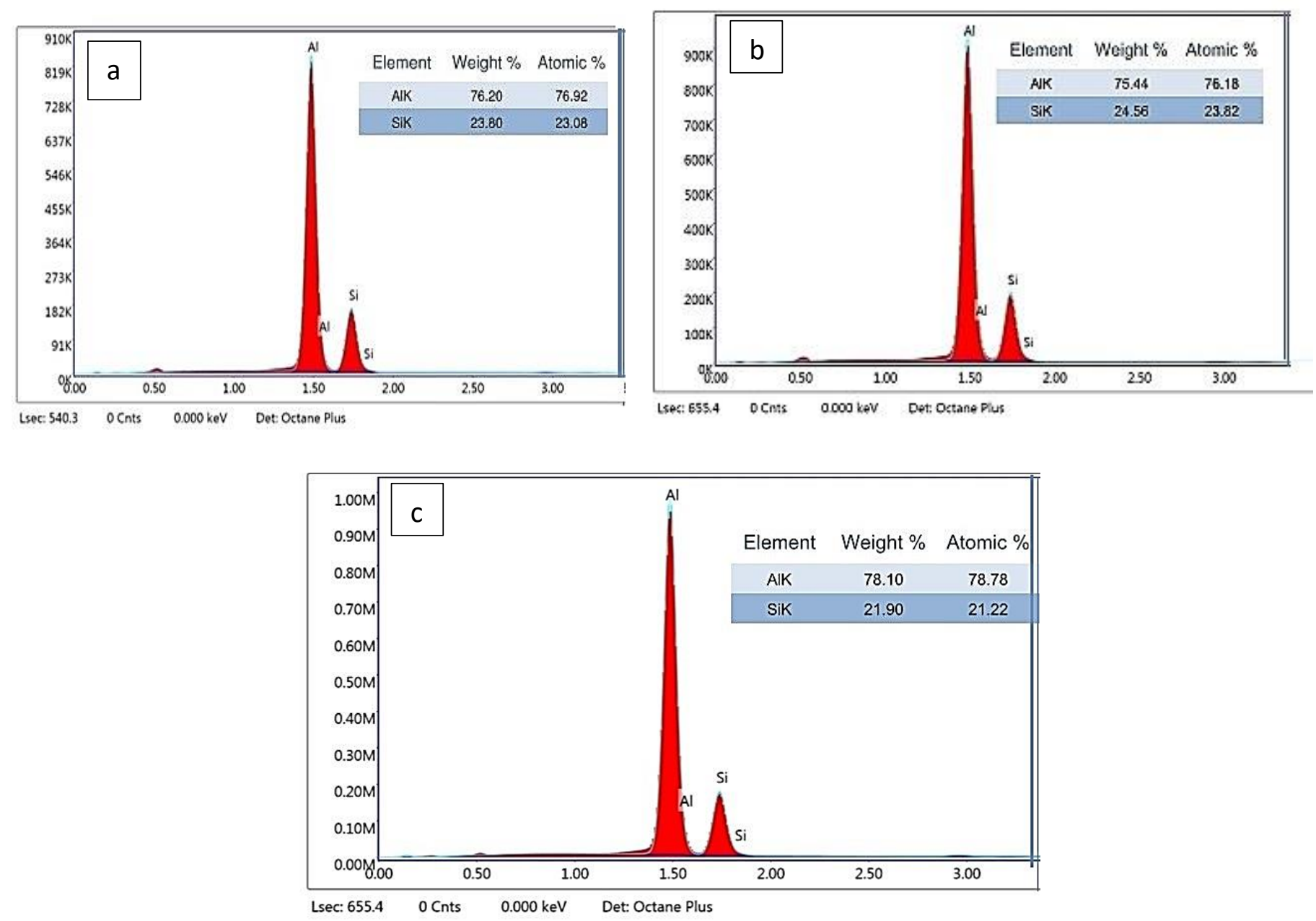

Fig.2: EDS analysis showing the composition at different locations in zone 1, (a) average composition of zone 1 , (b) average composition of zone 2, (c) eutectic composition in zone 2.

\section{Microstructural analysis}

The microstructure of zone 1 in Fig.1a, which is processed at $2000 \mathrm{~W}$ and $10 \mathrm{~mm} / \mathrm{s}$, exhibits a hypoeutectic structure in the lower part, becoming fully eutectic and hypereutectic above the interface. The refined structure, consisting of $\alpha$-Al dendrites and Al-Si eutectic occupies a volume of approximately 80 percent of the remelted zone while the rest is a dispersion of isolated primary silicon phase (Fig.3a). The primary Si crystals are distinguished by their complex and irregular shape with many side branches and with sizes ranging between 3 and $5 \mu \mathrm{m}$, while the eutectic structure shows a fibrous morphology with an average spacing of 75 $\mathrm{nm}$ (Fig.3b). The microstructure of zone 2, which was processed at the scanning speed (180 mm/s) is much finer than that shown in zone 1 and consists of relatively finer primary Si crystals of size about $2 \mu \mathrm{m}$ with columnar dendrites radiating around and near the primary Si, and a significant increase in the eutectic colonies of a spacing ranging between 30 to $50 \mathrm{~nm}$ (Fig.3c and d). The major difference between the microstructures of zone 1 and zone 2 apart from the refinement, is the decrease in the volume fraction of the $\alpha$-Al dendrites in the matrix with an increasing amount of the eutectic colonies (Fig. 3a and Fig.3c). Furthermore, the primary 
Si crystals are found to be partially surrounded by the $\alpha$-Al phase with many eutectics colonies grown directly from it (Fig.3c).

To achieve further refinement of the microstructural constituent of the Al-25wt.\%layer, a second remelting treatment was performed, but at $1000 \mathrm{~W}$ and $180 \mathrm{~mm} / \mathrm{s}$. The resulting solidified zone was $125 \mu \mathrm{m}$ deep. The average size of the primary Si flakes was reduced to $\leq 1.5 \mu \mathrm{m}$ (Fig.4 a-c). As the primary silicon became smaller, its morphology changes from star-like to blocky and granular with a slight tendency to branch laterally. From the other side, the Al-Si eutectic was modified and showed an interwoven fibrous structure of spacing ranging between 20 and $30 \mathrm{~nm}$. Most of the eutectic silicon fibers grew from the vicinity of the primary Si crystals and spreads randomly in different directions (Fig.4d).
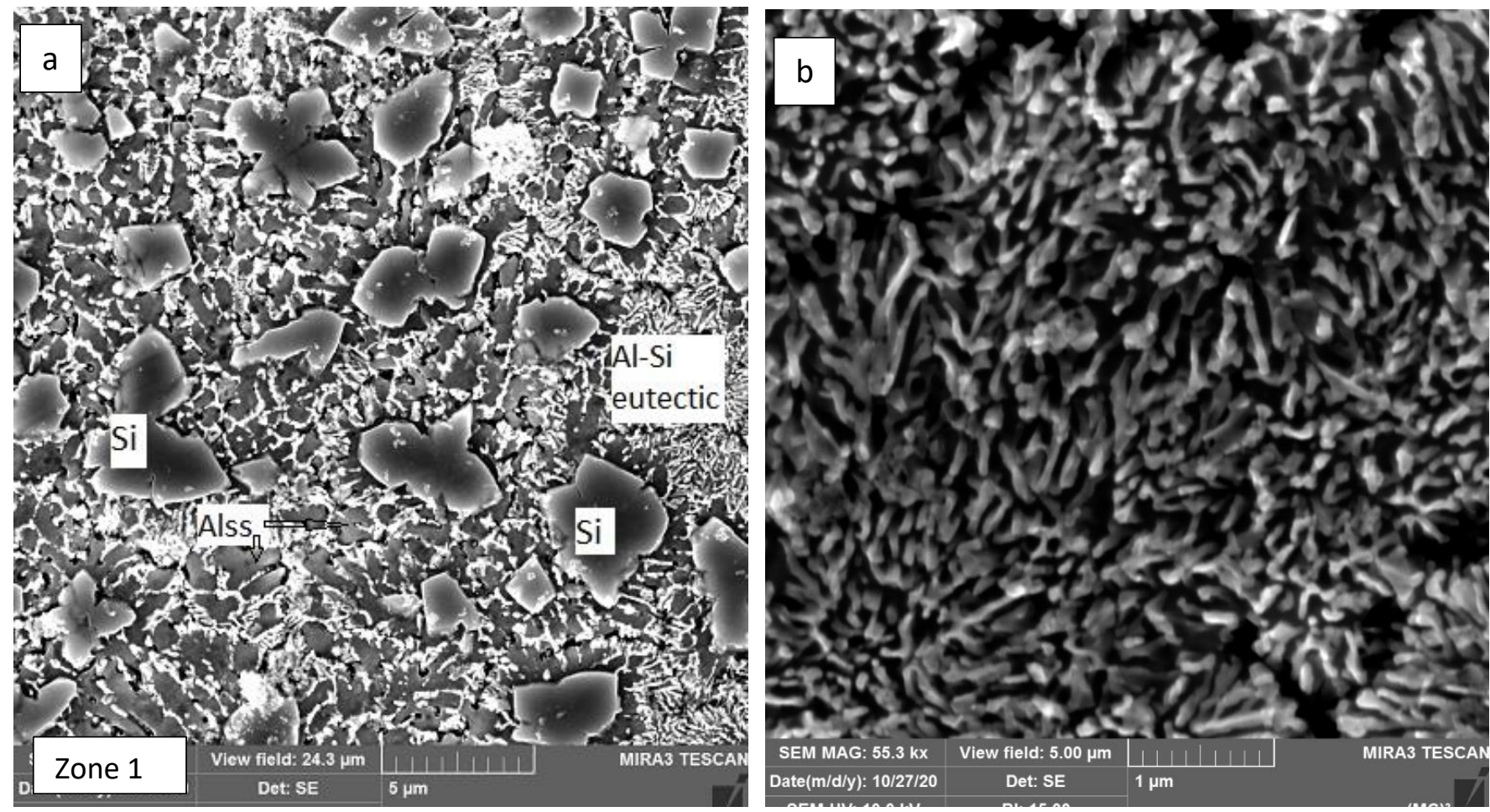

Fig.3: SEM micrographs were taken at different locations in the laser remelted zone of Al-25wt\%Si layer showing that the primary-Si crystals coexisted with the eutectic, (a) and (b) from the lower part, zone 1 $(2000 \mathrm{~W}, 10 \mathrm{~mm} / \mathrm{s},(\mathrm{c})$, and (d) were taken from the upper region (zone 2), (2000W, $180 \mathrm{~mm} / \mathrm{s}$ ). 

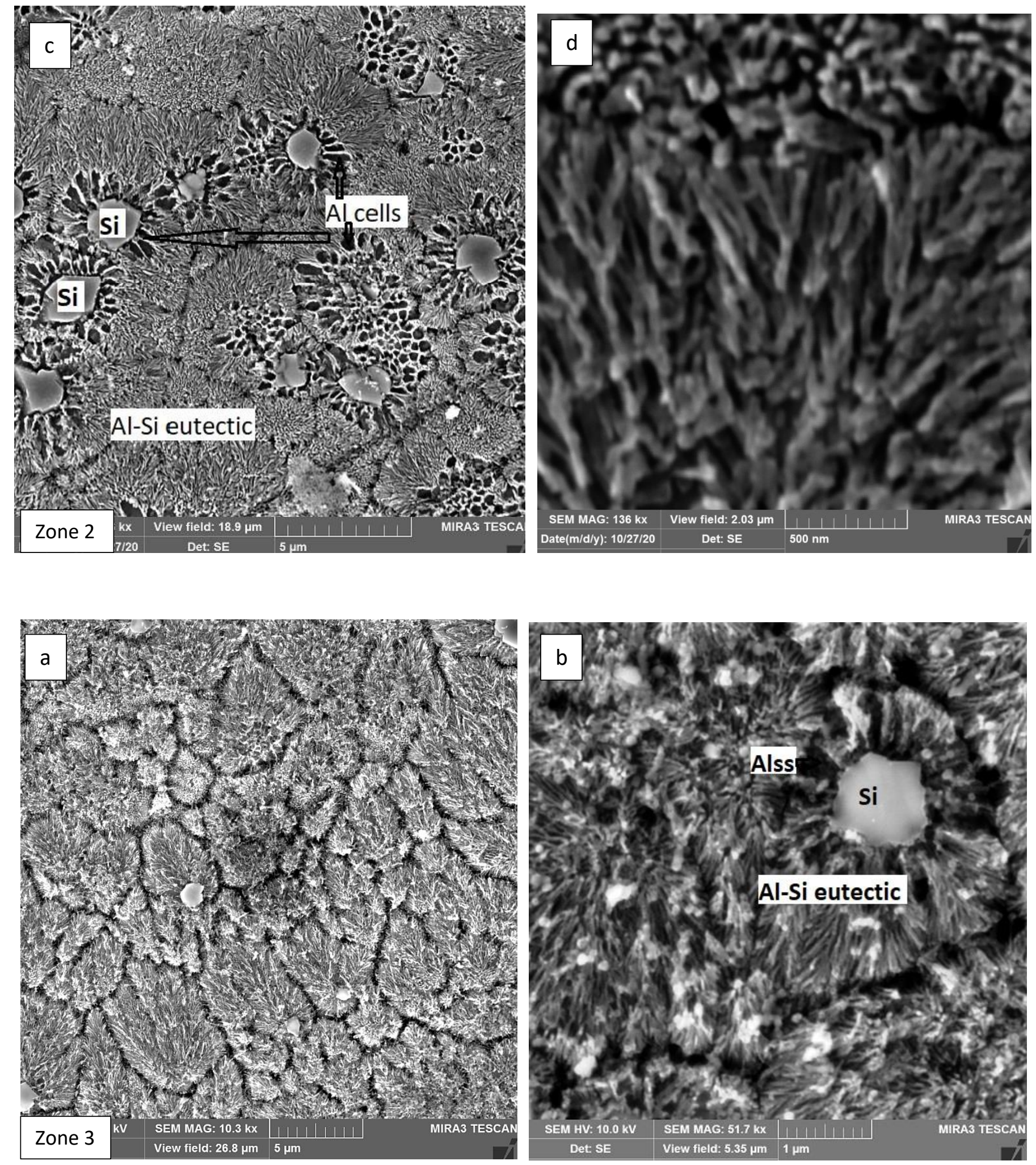

Fig.4. SEM micrographs showed the microstructure of laser remelted Al-25wt.\%Si layer at a speed of 180 $\mathrm{mm} / \mathrm{s}$ and laser power of $1000 \mathrm{~W}$ showing (a) fine eutectic colonies of size $5 \mu \mathrm{m},(\mathrm{b}-\mathrm{c}) \alpha-\mathrm{Al}$ dendrites and fibrous eutectic nucleated around the primary $\mathrm{Si}$, (d) fibrous eutectic. 

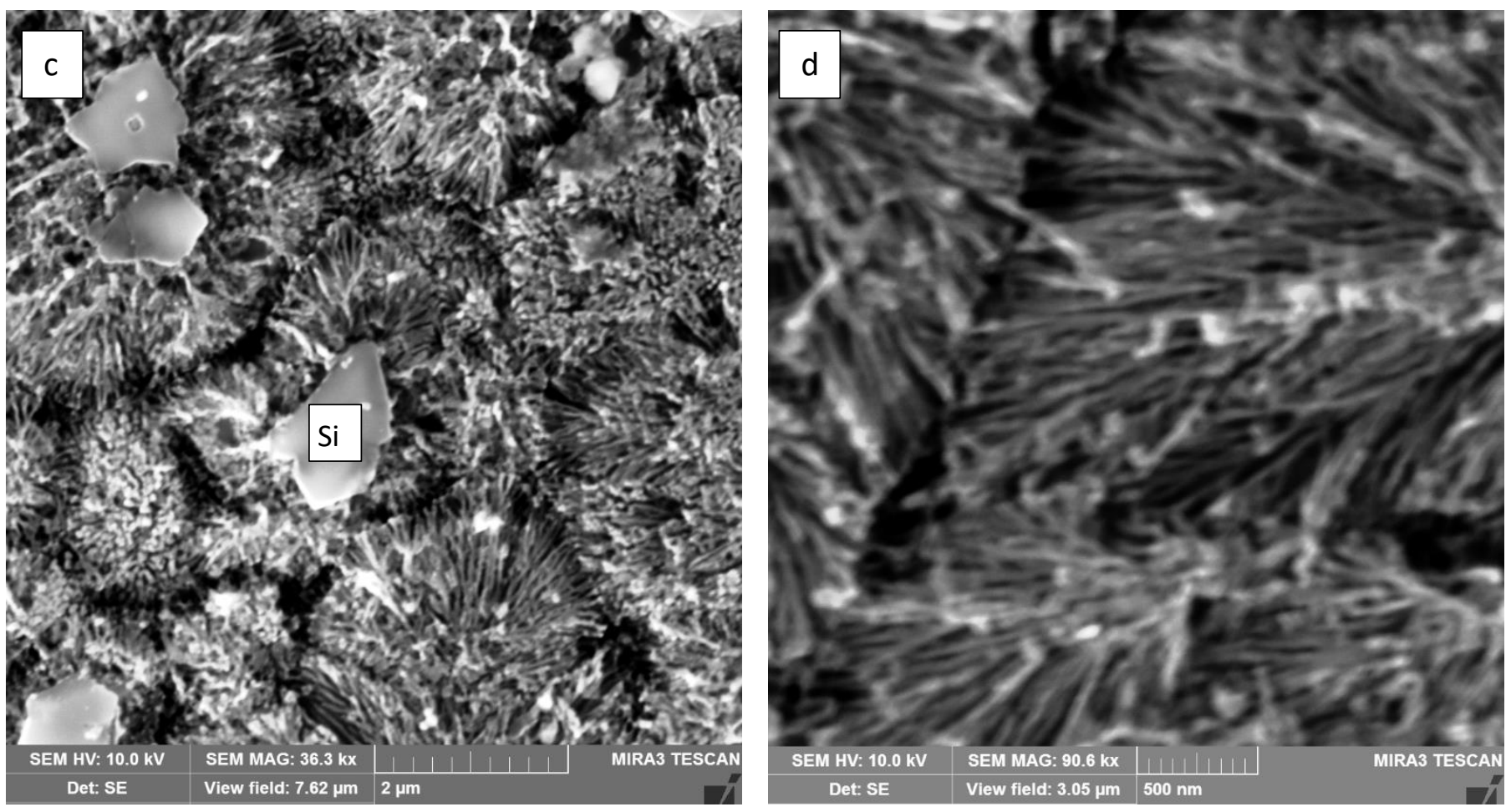

\section{Nanoindentation hardness}

Nanoindentation hardness (NIH) was measured in different zones in the remelted Al-25wt.\%Si alloyed layer including the fully eutectic and the hypereutectic regions, and the resulted indentation hardness was correlated with the eutectic spacing $(K)$. The result showed that the indentation hardness of the transverse section of the remelted Al-25wt.\%Si alloyed layer were 1.75, 2.55, and $3.15 \mathrm{GPa}$, which corresponds to the eutectic spacing, $\kappa$, of 50,35 , and $25 \mathrm{~nm}$, respectively. It is clear that as the heat input decreases, the melt depth became smaller and cooled rapidly so as a result, the eutectic spacing $K$ decreased, and the nanoindentation hardness increased. The maximum value obtained was $3.15 \mathrm{GPa}$ at the top of zone 3 , which displayed the finest structure with $\Lambda$, as small as $20 \mathrm{~nm}$. However, some regions in the upper part of zone 3 showed very high values in the range of 5.4 and $6.4 \mathrm{GPa}$. It is expected that the presence of fine primary silicon of sizes less than $1 \mu \mathrm{m}$ contributed to the high hardness value considering that the indentation of the primary silicon alone is approximately 10 GPa. The effect of the increased nanoindentation hardness with a decrease of the eutectic is presented in Fig.6. An empirical relationship followed this formula, $\mathrm{NIH}=\mathrm{K}(\kappa)^{-\mathrm{n}}$ where $\mathrm{NIH}$ is in GPa and $K$ in $\mathrm{nm}, \mathrm{K}$ and $\mathrm{n}$ are constants depends on the composition of the alloy. In the present work, the values of the constants $\mathrm{n}$ and $\mathrm{K}$ for $\mathrm{Al}-25 \mathrm{wt} . \% \mathrm{Si}$ were 0.55 and 15 , respectively. The general trend of increased strength in ultra-fine laser melted Al-Si fibrous eutectic is consistent with earlier studies [30]. 


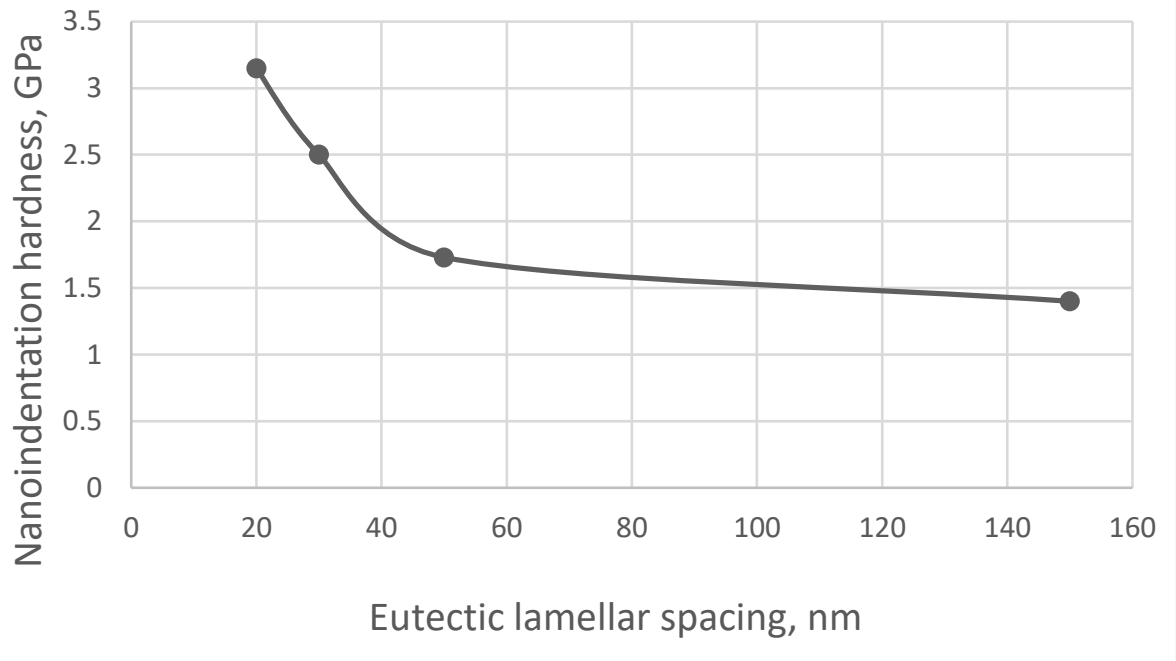

Fig. 5: Nanoindentation hardness as a function of eutectic spacing, measured in different locations of the transverse section of Al-25wt.\%Si alloyed layer.

\section{Microstructural characterization of tracklayer $2 \mathrm{~A}$.}

A cross-section of the tracklayer $2 \mathrm{~A}$, which was fabricated at a power $2000 \mathrm{~W}$ and a speed of $10 \mathrm{~mm} / \mathrm{s}$ and remelted at a faster scanning speed of $180 \mathrm{~mm} / \mathrm{s}$, is presented in Fig.6a. It is apparent from the figure that both zones 1 and 2 showed a high percentage and conglomeration of the primary Si phase in the center of the melted zone while at the edges, the concentration was lower. EDS analysis at different locations in zone 1 and zone 2, showed a silicon content in the $\mathrm{Si}$ - poor region ranged between 22 and $25 \mathrm{wt}$.\% Si while in the Si-rich region ranged between 29 and 33 wt.\% (Fig.6b). Based on the optical micrograph, SEM images, and the EDS results, the average content of silicon was estimated to be approximately $30 \mathrm{wt} . \% \mathrm{Si}$, which is higher than the 1A tracklayer. Microstructure analysis of the two zones showed a typical hypereutectic structure consisting of star-like primary Si phase, a high proportion of aluminum dendrites, and Al-Si eutectic. The average size of the primary Si in zone 1 and zone 2 , were $7 \mu \mathrm{m}$ and $4 \mu \mathrm{m}$, respectively. The resulting structure and the very small size of the primary Si were due to the high cooling rate associated with laser melting. Furthermore, the obtained sizes are much finer than those obtained by the casting process (50 to $100 \mu \mathrm{m}$ ) and much close to those obtained using the rapid solidification technique $(2-10 \mu \mathrm{m})$ [26-30].

To achieve further refinement of the primary Si crystals to the nanoscale level, the surface of the Al-30wt.\%Si alloyed layer (tracklayer 2A) was subjected to several overlapping laser remelting at a fast speed of $180 \mathrm{~mm} / \mathrm{s}$ and powers of 1000,800 , and $600 \mathrm{~W}$, respectively. A typical cross-section and a top view of the remelted surface layer are shown in Figures.7 a and b, respectively. Fig. $7 b$ showed segregation of very fine primary Si near the top surface in all the remelted zones. More details about the microstructure of each zone are presented in Figures 8 to 11. Figure 8 showed the microstructure of zone 2, which was remelted at 2000W and showed a fine hypereutectic structure consisting of primary Si crystals of sizes ranging from 2 to $3 \mu \mathrm{m}$, embedded in a hypoeutectic matrix containing $\alpha-\mathrm{Al}$ dendrites and Al-Si eutectic. Figures 9 a and b present the 
microstructure of zone 3, which was remelted at $1000 \mathrm{~W}$ and showed a further refinement of the microstructural constituent as the size of the PSi crystals was reduced to $1-2 \mu \mathrm{m}$ and increased in the proportion of the eutectic structure. Zone 3 marks the beginning of a formation of a modified eutectic resembling fur-like shape (Figure 9b) emerging from the pre-existing primary Si crystals and branched out. Figures 10 a to d show the microstructure of zone 4, which is remelted at the lowest power $800 \mathrm{~W}$ and experienced the highest cooling rate. There was a significant increase in the quantity of the modified eutectic and a decrease in the amount of $\alpha-\mathrm{Al}$ dendrites around the primary $\mathrm{Si}$ and within the matrix. Furthermore, the sizes of the primary Si crystals were refined to $1 \mu \mathrm{m}$ while the eutectic spacing was reduced to less than 20 nm.
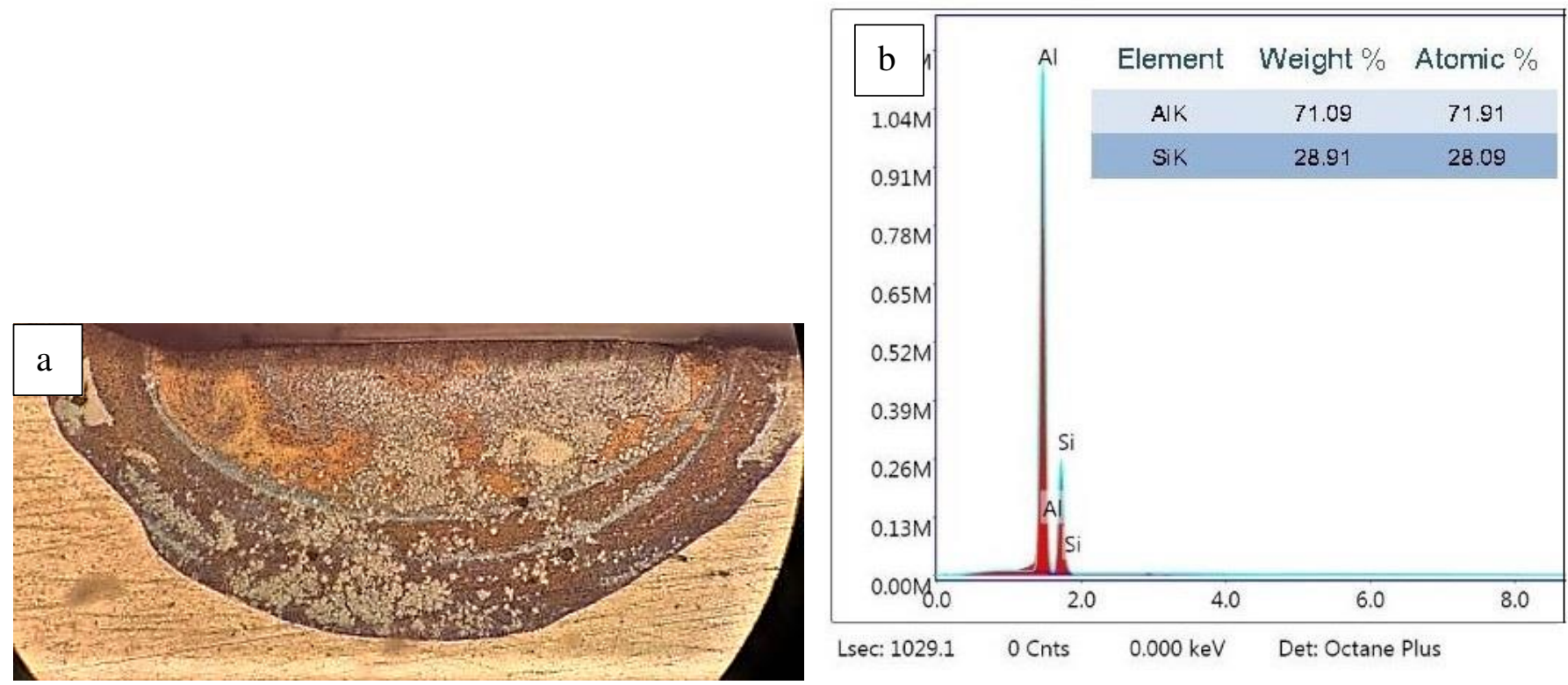

Fig.6: A cross-section of track layer (2A) fabricated at $2000 \mathrm{~W}, 10 \mathrm{~mm} / \mathrm{s}$ and remelted at $180 \mathrm{~mm} / \mathrm{s}$, (b) EDS spectrum taken from the center of zone 2 . 

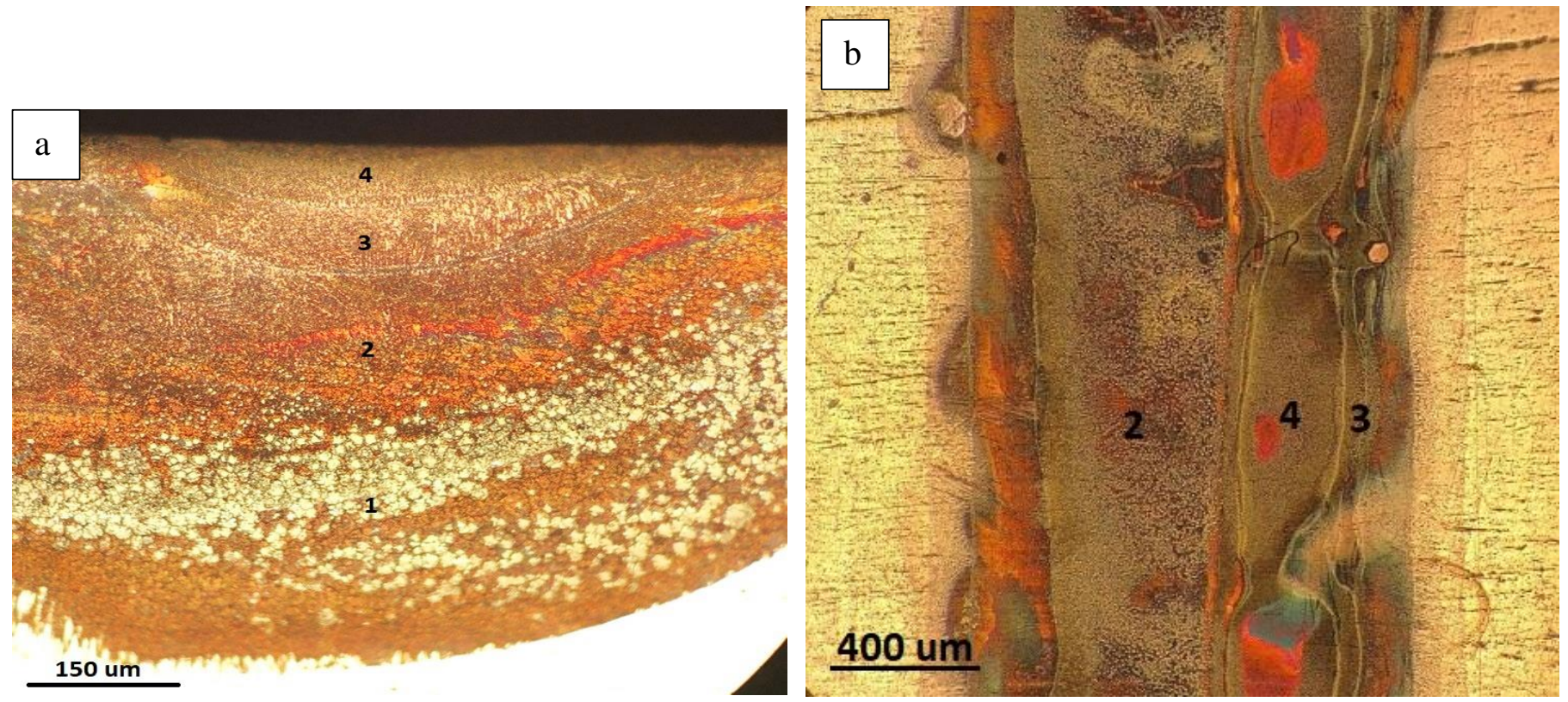

Fig.7: Optical micrograph shows a cross-section and top view of the 1A track layer (Al-30wt.\%Si), which is laser remelted at different conditions, zone 2,3, and 4 processed at powers $2000 \mathrm{~W}, 1000 \mathrm{~W}$, and $800 \mathrm{~W}$, respectively.
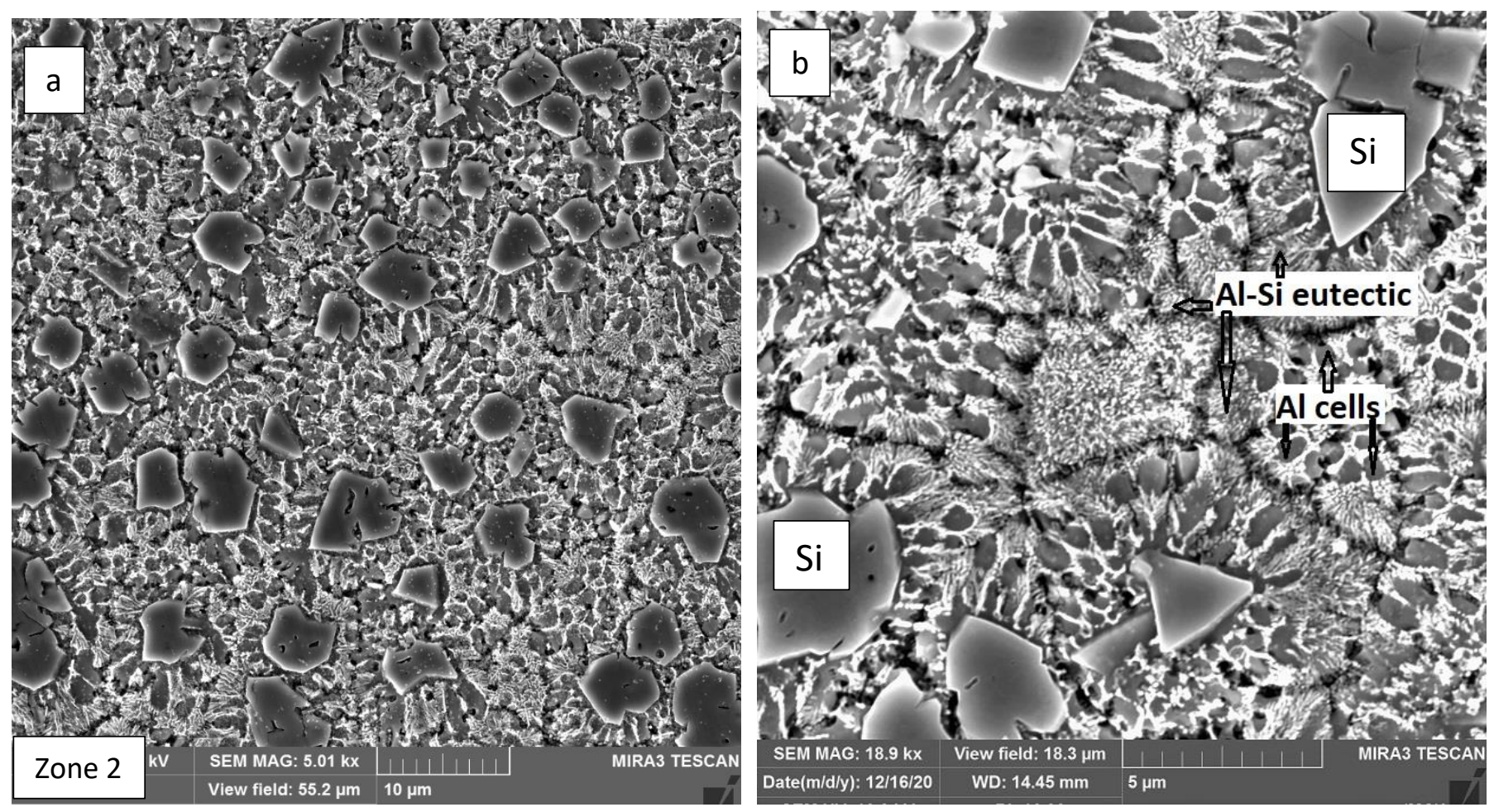

Fig.8. (a) SEM micrograph showed the microstructure Al-30wt.\%Si layer (zone 2), which was remelted 2000W and 180 mm/s. (b) Enlargement of Fig.8a illustrated primary Si, $\alpha$-Al, and Al-Si eutectic. 

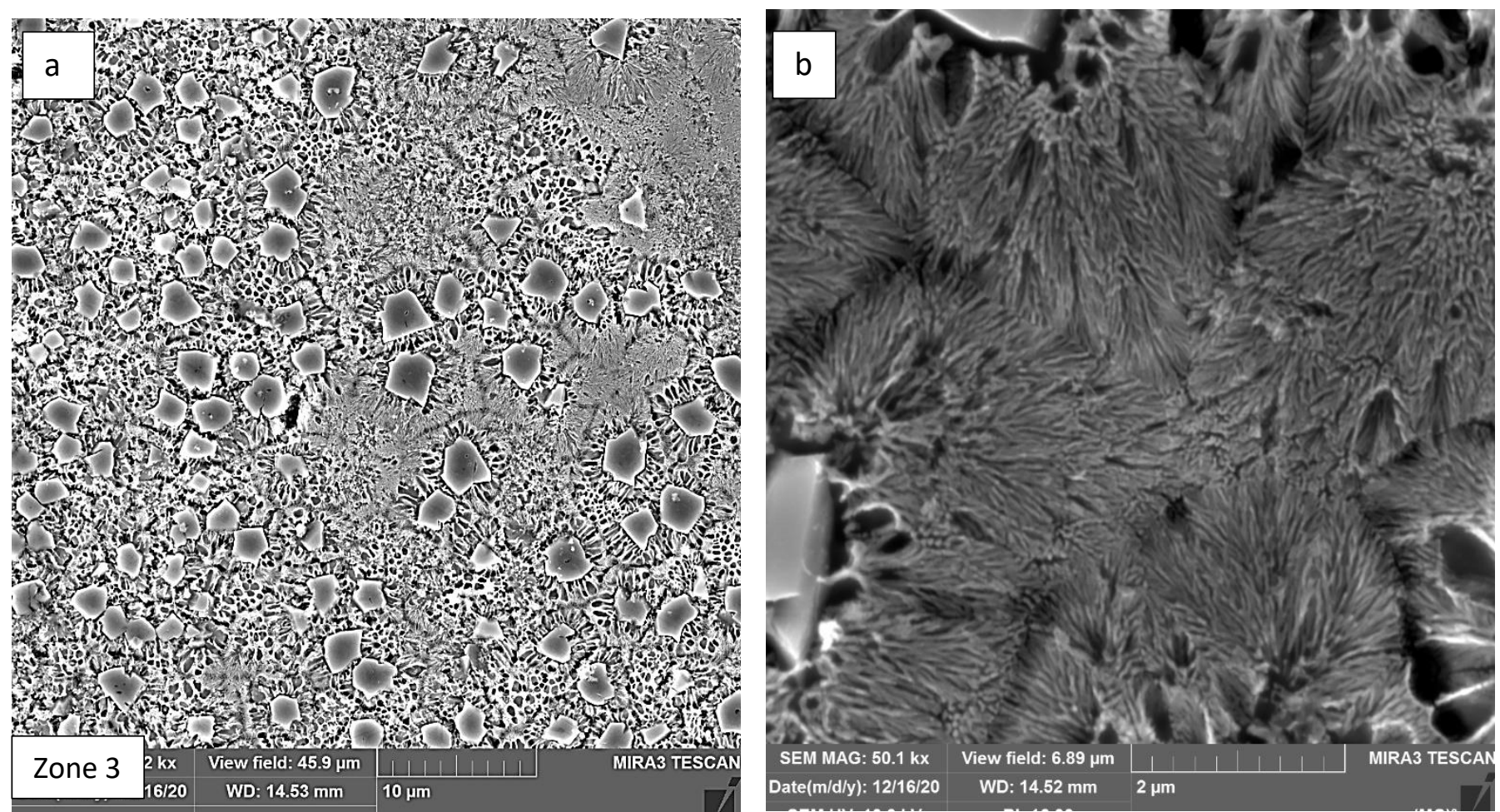

Fig.9. (a) SEM micrograph showed the microstructure Al-30wt.\%Si layer (zone 3), which was remelted $1000 \mathrm{~W}$ and $180 \mathrm{~mm} / \mathrm{s}$. (b) Enlargement of Fig.10a showing a high proportion of fine eutectic and PSi.
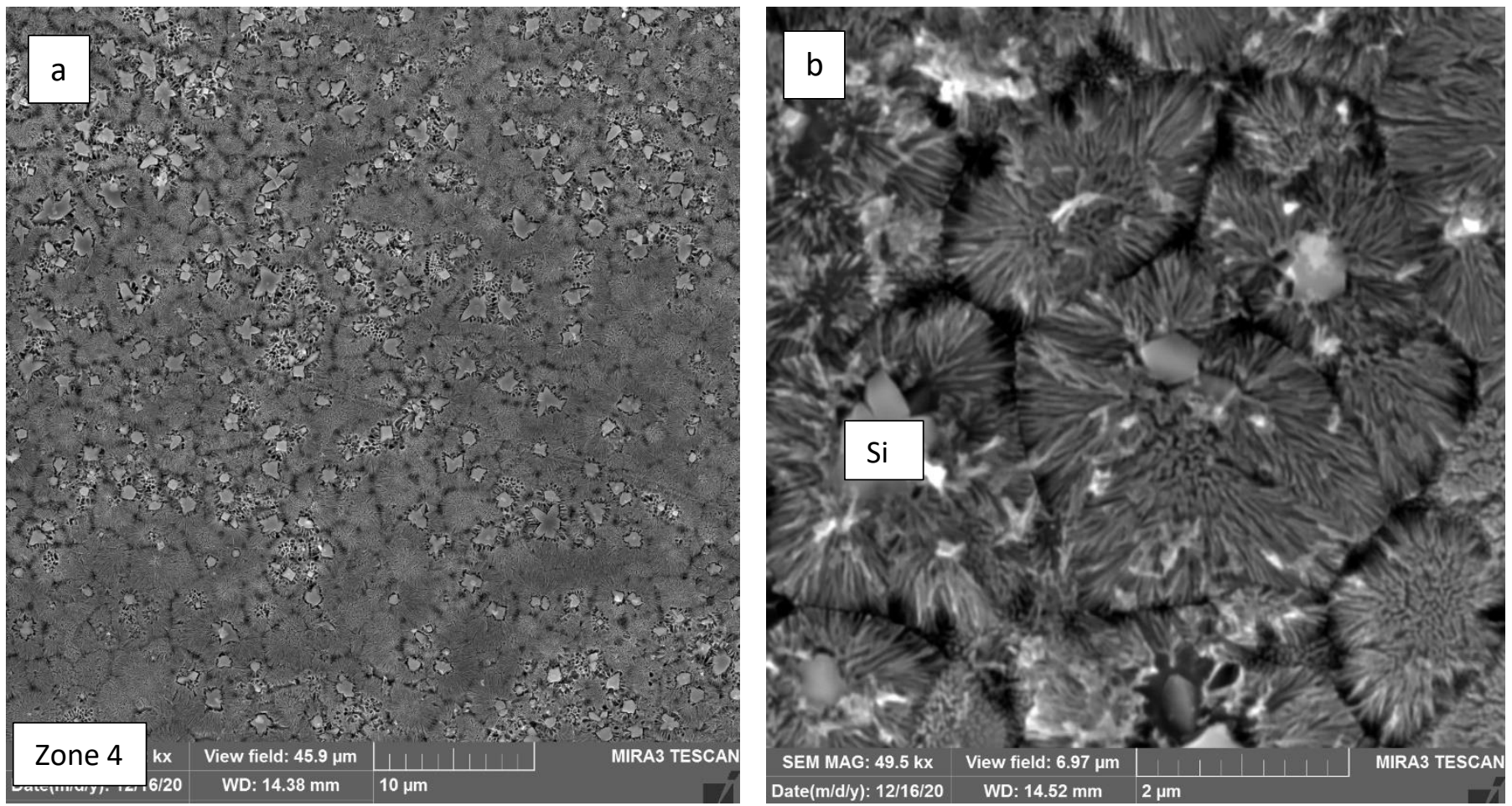

Fig. 10. (a-d) SEM micrographs showed the microstructure of the Al-30wt.\%Si layer zone (zone 4), which was remelted at the lowest power $(800 \mathrm{~W})$ and fast speed $(180 \mathrm{~mm} / \mathrm{s})$ showing a modified eutectic. 

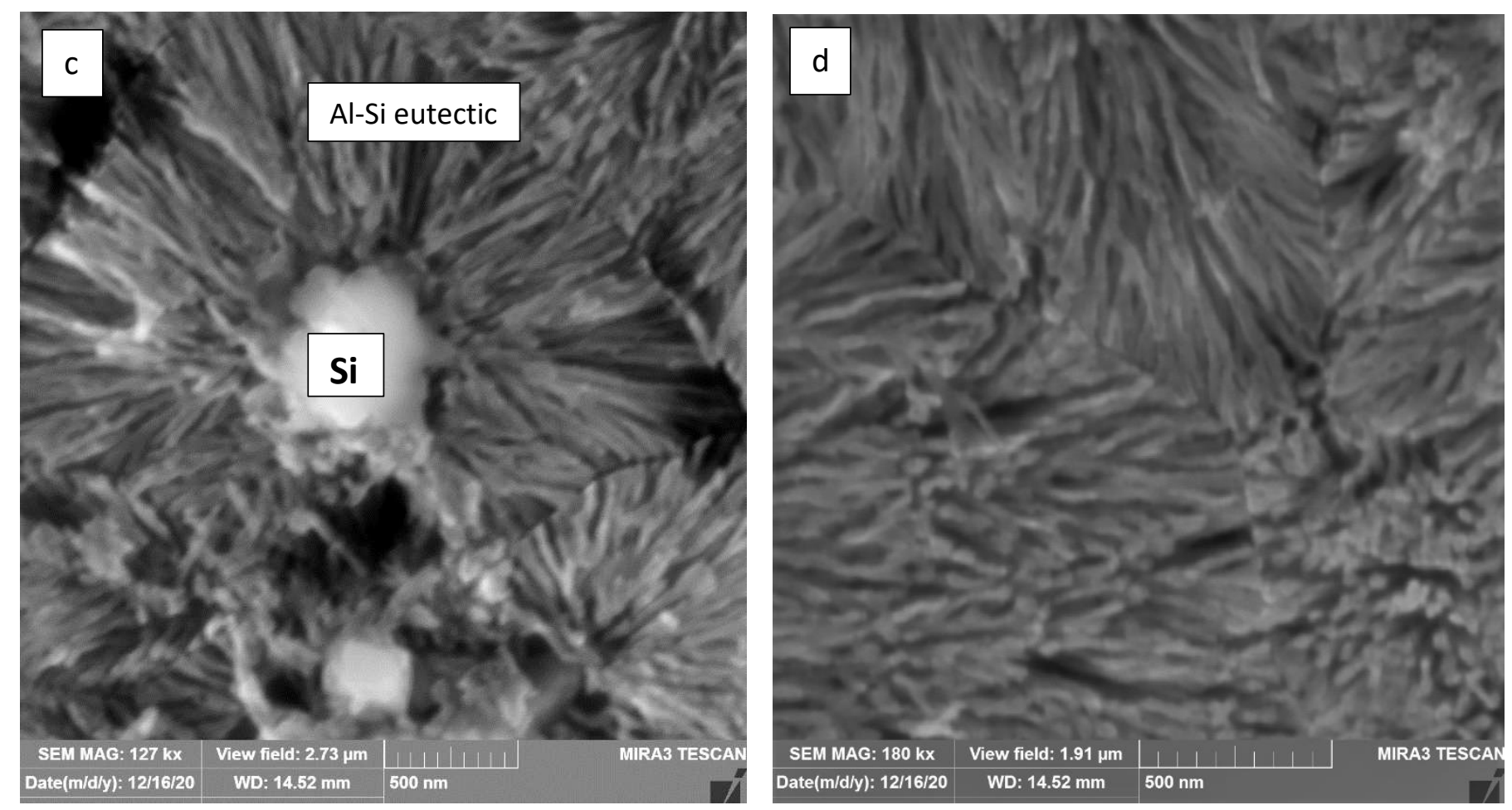

\section{TEM analysis}

TEM study at different regions in the remelted Al-30wt.\%Si layer showed that the primary silicon crystals and the eutectic silicon contained a high density of parallel twins while the $\alpha$-Al phase contains dislocations and ultrafine twinned silicon particles (Fig.11 a-d). The twins in the primary Si crystals were parallel and have different directions with spacing ranging between 5 and 20nm (Fig.11b). The eutectic silicon exhibits different morphologies. Figs.12 a and b show worm-like Si particles of different lengths nucleated and grow in the $\alpha$ Al cells/dendrites in addition to the nano-sized $\mathrm{Si}$ crystals which precipitated during cooling to room temperature. Fig.13 a and b show Al-Si eutectic silicon of nanosized fibrous morphology. It is apparent from the figure that as the laser remelt power is reduced, the eutectic size and spacing became much finer. The fibrous eutectic in zone 4, which experience the highest cooling rate showed the smallest spacing of approximately 10 to $15 \mathrm{~nm}$. TEM examination revealed a high density of parallel twins extended along the length of the silicon fiber (Fig. 11b). This observation supported the twin plane re-entrant edge (TPRE) theory that the formation of twins accelerates the growth of the eutectic silicon since silicon growth occurs more readily at the re-entrant edge [32]. 

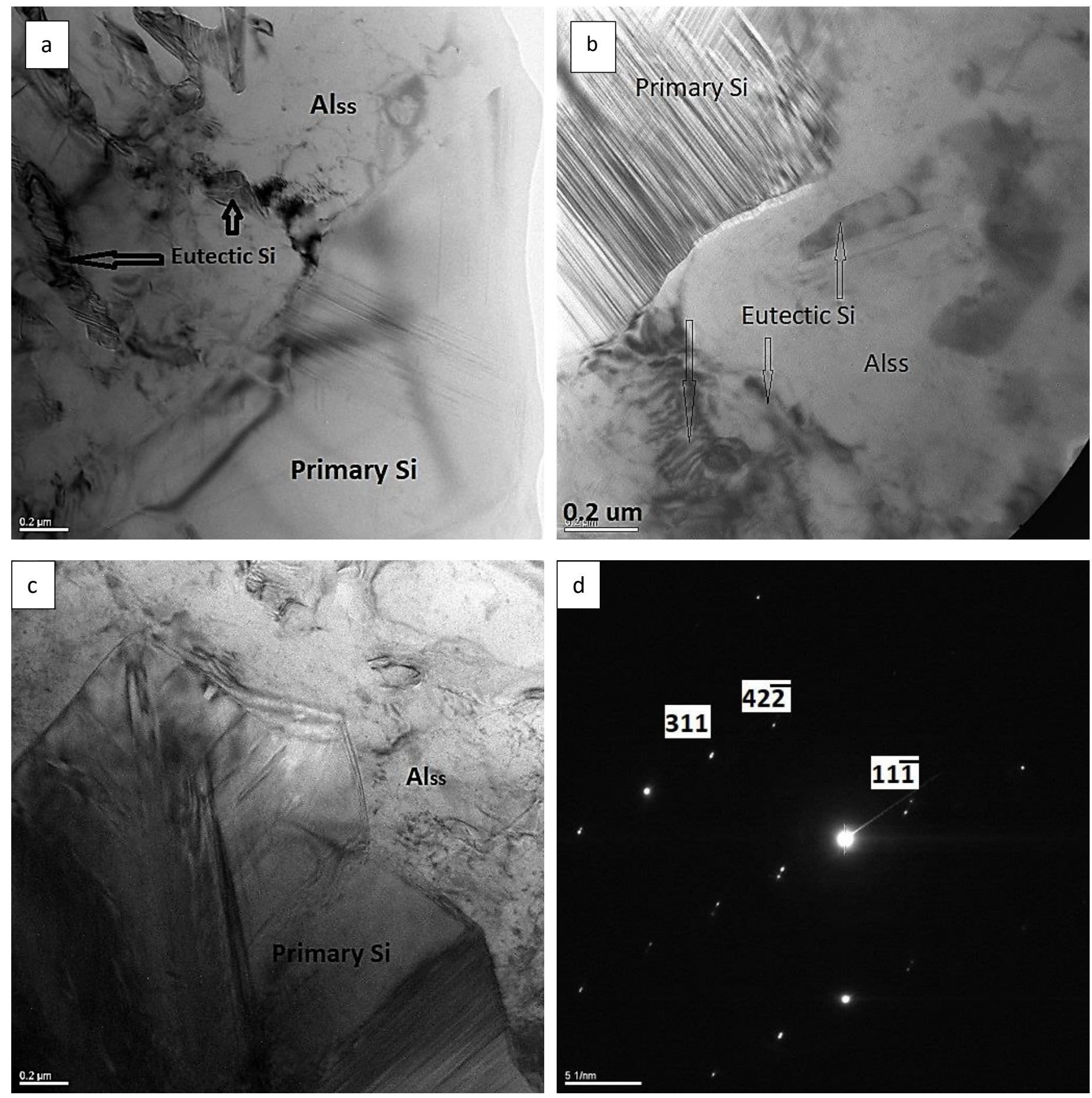

Figure11 (a-c). TEM micrographs were taken from the least cooled Al-30wt.\%Si alloyed layer (zone 2) showing primary Si crystals contain multiple twins, eutectic Si, and $\alpha$-Al (d) SADP was taken from primary silicon, which is shown in Fig.11b, zone axis is [121]. The spot-splitting is consistent with internal twinning. 

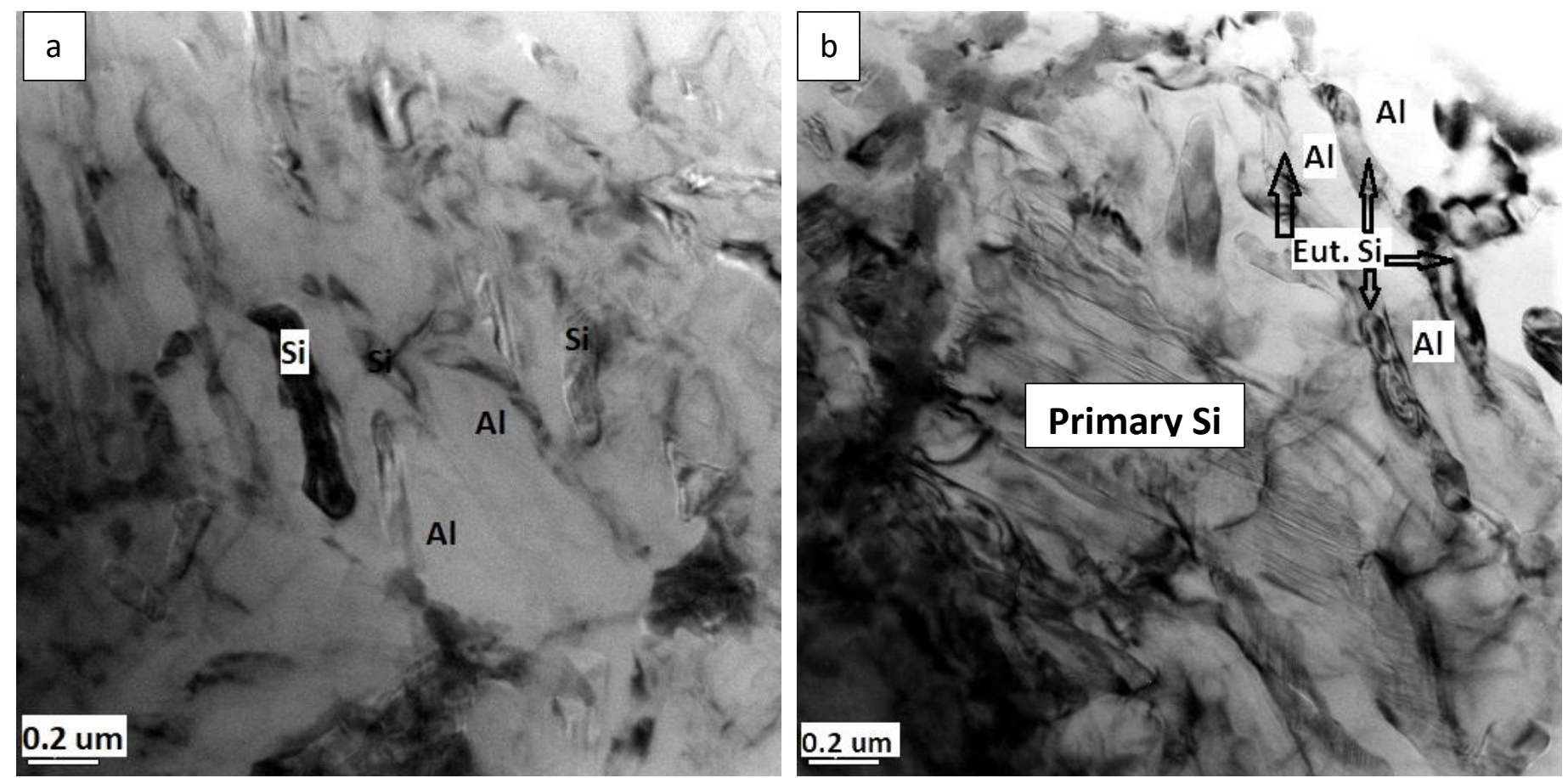

Fig.12 (a-b). TEM micrographs were taken from the Al-30wt.\%Si alloyed layer, laser remelted at a scan speed of $180 \mathrm{~mm} / \mathrm{s}$, and power 2000W (zone 2 in Fig.7) showing worm-like silicon particles of different lengths within the $\alpha$-Al cells or dendrites.
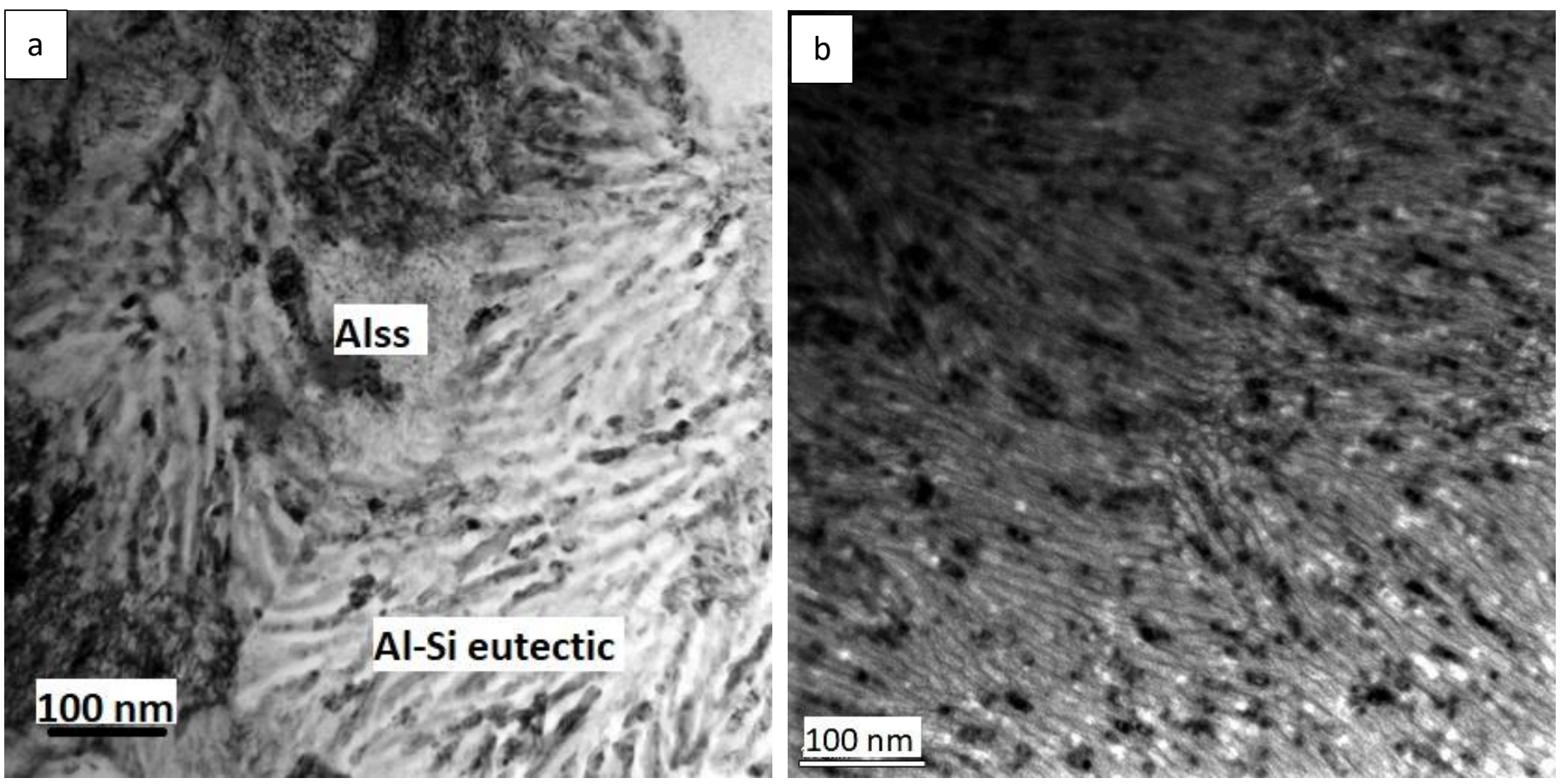

Fig.13 (a-b).TEM micrographs show the nanosized fibrous Al-Si eutectic in Al-30wt.\%Si alloyed layer, laser remelted at a scan speed of $180 \mathrm{~mm} / \mathrm{s}$ and powers (a) 1000W (zone 3, Fig.7), (b) 800W (zone 4, Fig.7). As the laser remelt power is reduced, the eutectic become much finer. 


\section{Cooling rate}

In this study, the cooling rate for Al-Si alloyed layers was calculated using what is known as the Eagar-Tsai approach which is based on the Rosenthal equation [33,34]. The model is based on conduction and considers the laser heat input as a Gaussian area, which is more realistic than point input approaches. Thermo-physical properties of the Al-Si alloys were kept constant and calculated through the mixing of mass percent for different alloys. Solution for equation 1 is only possible with numerical integration. Additionally, discretization of an area of interest (in other words laser material interaction region) is a must. Those requirements increase the computation significantly. Therefore, it was submitted to a workstation after defining the boundary conditions and input values (Thermophysical properties and laser processing parameters, [35]). To reduce computation time, the discretized matrix was solved 10 times, each of which with $0.01 \mathrm{~ms}$ time increment. Upon completion, heat history and time steps were used for cooling rate calculations. Results are shown in Table 2.

Table 2: The overall effect of the laser rapid remelting at different powers or heat inputs $(\mathrm{P} / \mathrm{v})$ on the melted depths, average cooling rates, PSi sizes, and eutectic spacings of the Al-25wt.\%Si and Al-30wt.\%Si alloyed layers.

\begin{tabular}{|c|c|c|c|c|c|c|c|c|}
\hline \multirow{2}{*}{$\begin{array}{l}\text { Laser track } \\
\text { layer }\end{array}$} & \multicolumn{3}{|c|}{ Laser processing parameters } & \multirow[b]{2}{*}{ Location } & \multirow{2}{*}{$\begin{array}{l}\text { Remelted } \\
\text { depth, } \mu \mathrm{m}\end{array}$} & \multirow{2}{*}{$\begin{array}{l}\text { Average } \\
\text { cooling rate } \\
{ }^{\circ} \mathrm{C} / \mathrm{s}\end{array}$} & \multirow{2}{*}{$\begin{array}{c}\text { PSi size } \\
\mu \mathrm{m}\end{array}$} & \multirow{2}{*}{$\begin{array}{l}\text { Spacing } \\
\Lambda, \mathrm{nm}\end{array}$} \\
\hline & Power, W & $\begin{array}{l}\text { Speed } \\
\mathrm{mm} / \mathrm{s}\end{array}$ & $\begin{array}{l}\text { Heat input } \\
\mathrm{J} / \mathrm{mm}\end{array}$ & & & & & \\
\hline \multirow{3}{*}{$\begin{array}{l}1 \mathrm{~A} \\
\mathrm{Al}-25 \mathrm{wt} . \% \mathrm{Si}\end{array}$} & 2000 & 10 & 200 & Zone 1 & 500 & $4.5362 \times 10^{3}$ & $6-8$ & 50 \\
\hline & 2000 & 180 & 11.11 & Zone 2 & 250 & $6.9329 \times 10^{4}$ & $3-5$ & 30 \\
\hline & 1000 & 180 & 5.5 & Zone 3 & 150 & $7.1828 \times 10^{4}$ & $1-2$ & 20 \\
\hline \multirow[t]{2}{*}{$2 \mathrm{~A}$} & 2000 & 10 & 200 & Zone 1 & 600 & $4.6236 \times 10^{3}$ & $3-6$ & 150 \\
\hline & 2000 & 180 & 11.11 & Zone 2 & 300 & $7.1175 \times 10^{4}$ & $2-3$ & 50 \\
\hline \multirow[t]{2}{*}{ Al-30wt.\%Si } & 1000 & 180 & 5.5 & Zone 3 & 150 & $7.6624 \times 10^{4}$ & $1-3$ & 25 \\
\hline & $\begin{array}{l}800 \\
600\end{array}$ & $\begin{array}{l}180 \\
180\end{array}$ & \begin{tabular}{|c|}
4.45 \\
Partial melting
\end{tabular} & $\begin{array}{c}\text { Zone } 4 \\
-----\end{array}$ & $\begin{array}{l}70 \\
---\end{array}$ & $9.0926 \times 10^{4}$ & $\begin{array}{l}0.5-2 \\
---\end{array}$ & $\begin{array}{l}10 \\
-----\end{array}$ \\
\hline
\end{tabular}

Fig.14a and $\mathrm{b}$ showed clearly that increasing the cooling rate caused a great reduction in the sizes of the primary Si and the eutectic spacing to a nanoscale. Although the two curves have the same trend the decrease of the eutectic spacing is much steeper especially at the highest cooling rate. This can be seen more clearly in the TEM micrographs in Figs.13d, which showed a significant decrease of the eutectic spacing to approximately $10-15 \mathrm{~nm}$ at the highest cooling rate. 

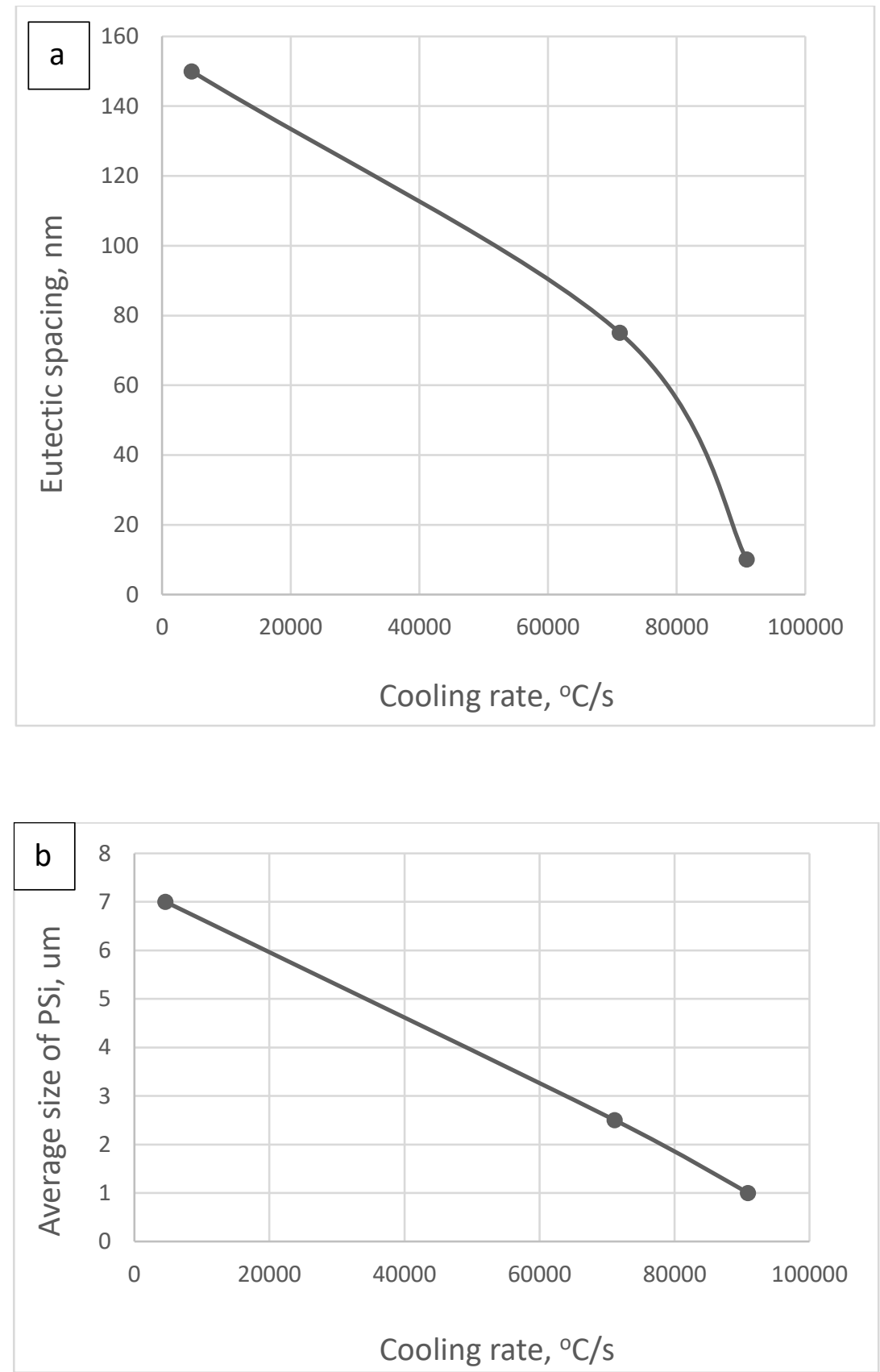

Fig. 14. (a) Variation of the eutectic spacing with cooling rate, (b) variation of the primary silicon size with the cooling rate for $\mathrm{Al}-30 \mathrm{wt} . \% \mathrm{Si}$ alloyed layer laser remelted at different heat inputs.

\section{Discussion}

Results of the laser rapid remelting of the $\mathrm{Al}-25 \mathrm{wt} . \% \mathrm{Si}$ and $30 \mathrm{wt} . \% \mathrm{Si}$ alloyed layers, which were processed at relatively lower laser powers and a higher scan speed, showed the potency of the cooling rate not only in the refining of the silicon size but also in reducing the quantity of the primary Si crystals, decreasing the amount of the aluminum dendrites, and also triggering the eutectic Si to nucleate heterogeneously from the primary silicon 
phase and branched out of it. Furthermore, the increase of the cooling rate caused a shift in the eutectic composition toward a high silicon content reaching $20 \mathrm{wt} . \% \mathrm{Si}$ or slightly more, which is far more than the value reported in the Al-Si equilibrium phase diagram $(12.6 \mathrm{wt} \% \mathrm{Si})$. In the present results, the microstructure of the fabricated and the remelted layers are hypereutectic and consistent with the Al-Si phase diagram, but with great refinement in the scale of all the phases (primary $\mathrm{Si}, \alpha-\mathrm{Al}$, and eutectic $\mathrm{Si}$ ). Solidification of Al-25 and $30 \mathrm{wt} . \% \mathrm{Si}$ alloyed layers at cooling rates commence with the nucleation of the primary $\mathrm{Si}$ nucleus. Once the Si nuclei formed, it grows by rejecting aluminum atoms and accumulate them around the vicinity of the silicon crystals, causing undercooling in the surrounding area leading to the nucleation and growth of the aluminum dendrites around the primary $\mathrm{Si}$. Upon further cooling, the aluminum dendrite continues to nucleate and grow rapidly by rejecting Si atoms on both sides of the dendrite. When the temperature reached the eutectic, the remaining liquid solidified forming Al-Si fibrous eutectic. The final solidified microstructure contains a high amount of aluminum dendrites, which upon further cooling to room temperature, begins with the precipitation of nanosized silicon particles. The solidification path will follow this sequence, $\mathrm{L} \rightarrow$ primary $\mathrm{Si}$. $+\mathrm{L}, \mathrm{L} \rightarrow$ primary $\mathrm{Si}$ $+(\mathrm{Al}$ around the primary $\mathrm{Si})+\mathrm{L}, \mathrm{L} \rightarrow$ primary $\mathrm{Si}+$ Alden. $+\mathrm{L}, \mathrm{L} \rightarrow$ primary $\mathrm{Si}+\mathrm{Al}+$ Eutectic. $(\mathrm{Al}+\mathrm{Si})$. Due to the high thermal conductivity of the Al phase as compared to the Si and the slow growth of the silicon phase, the eutectic formed by nucleation of the Al phase first, which force the silicon atom to occupy the space between the $\mathrm{Al}$ dendrites. However, under a very rapid cooling condition, as in the case of the remelting of the Al-25 and 30wt.\% Si layers at the fastest speed and low heat input, the highest cooling rate led to a reduction in the amount of aluminum that formed around the primary Si crystals, which acted as a nucleus for the growth of the eutectic aluminum phase and this will trigger the eutectic silicon to grow quickly upon the underlying solidified zone of primary $\mathrm{Si}+$ eutectic and spread massively in different directions forming a radiant rose.

On the other side, observations by the TEM micrographs at higher magnification demonstrate that most of the primary silicon contains parallel and multiple twins, which have a major contribution to the rapid growth of the eutectic silicon. These results are consistent with the TPRE mechanism [32], which indicate that twins influence the growth and cause branching and twisting of the Si fibers. The formation of heavily twinned Si fibers is reported by many researchers. Nogita et.al. [36] studied the effect of modifier elements (ca, Ba, Y, and Yb) on the A356.0 alloy, and all the modified eutectic silicon showed higher twin densities than the unmodified. It is reported that twins catalyze crystal growth leading to the formation of complex and more faceted morphology. Another factor that made the silicon phase twin easily is the low stacking fault formation energy of the silicon [37].

\section{Conclusions}

The results of this study show the potential of the laser melting technique in the fabrication of Al-25wt.\%Si and Al-30wt.\%Si alloyed layers with nanoscale structures on the surface of commercial purity aluminum substrate. The microstructure consisted of fine primary silicon crystals of size 5 to $7 \mu \mathrm{m}$ surrounded by $\alpha$-Al dendrites and immersed in the Al-Si eutectic. By laser rapid remelting technique at a fast speed $(180 \mathrm{~mm} / \mathrm{s})$ and low powers (1000W and less), a greater structural refinement was achieved as the size of the primary silicon particles was decreased to less than $1 \mu \mathrm{m}$ as well as the fibrous eutectic spacings were reduced to approximately 10-15 
$\mathrm{nm}$. The higher cooling rate resulted in a great reduction in the quantity of the $\alpha-\mathrm{Al}$ dendrites, triggered the $\mathrm{Si}$ eutectic to grow rapidly on pre-existing primary $\mathrm{Si}$ templates and, increased the proportion of the fibrous eutectic substantially. Both the primary Si and the eutectic Si exhibited a high density of twins. As a result of the refinement and decrease in the eutectic spacing, the nanoindentation hardness was increased to $3.15 \mathrm{GPa}$.

\section{Acknowledgments}

JH, MK, and AM acknowledge financial support from DOE-Basic Energy Science Grant no: [DE-SC0016808].

\section{References}

1. Dwivedi, D. Production and Properties of Cast Al-Si Alloys, Publisher: New Age International, October (2013).

2. Francisco, C. et al. Al-Si Alloys: Automotive, aeronautical, and aerospace applications, Springer International Publishing AG (2017).

3. Pacz A., U.S. Patent No. 1387900 (1920).

4. Hanna, M. D., Lu, S. Z. \& Hellawell, A. Modification in the aluminum-silicon system. Metall. Mater. Trans. A,15 (3), 459-469 (1984).

5. Liu, Q.Y. et al. Modification of aluminum-silicon alloys with sodium. Acta Metall. et Mater. 39 (11), 2497$2502(1991)$.

6. Liu, G. et al. The influence of strontium addition on wear properties of Al-20 wt. \% Si alloys under dry reciprocating sliding condition. Mater. Des. 32, 121-126 (2011).

7. Nogita, K., McDonald, S. D. \& Dahle, A. K. Eutectic modification of Al-Si alloys with rare earth metals. Mater. Trans. 45 (2), 323-326 (2004).

8. Li, D., Zuo, M., Zhang, Q. \& Liu, X.The investigation of continuous nucleation and refinement of primary Si in Al-30Si mushy zone. J. Alloys Compd. 502, 304-309 (2010).

9. Wu, Y., Wang, S., Li, H. \& Liu, X. A new technique to modify hypereutectic Al-24\%Si alloys by a-Si-P master alloy. J. Alloys Compd. 477, 139-144 (2009).

10. Li, Q. et al. Effect of rare earth cerium addition on the microstructure and tensile properties of hypereutectic Al-20\%Si alloy. J. Alloys Compd. 562 (15), 25-32 (2013).

11. Weixi, S. et al. Effect of neodymium on primary silicon and mechanical properties of hypereutectic Al-15

\% Si alloy. J. Rare Earths. 28I, 367-370 (2010).

12. Kun, Y. H. \& Di, Z. Modification of pure rare earth metals La on as-cast hypereutectic Al-17 \% Si alloy Trans. Nonferrous Met. Soc. China, 13 (2), 358-364 (2003). 
13. Xia, T., La, Y., Li, P. \& Fan, F. Effects of rare earth Er addition on microstructure and mechanical properties of hypereutectic Al-20\% Si alloy. Mater. Sci. Eng. A, 588 (20), 97-102. (2013).

14. Choi, H. \& Li, X. Refinement of primary Si and modification of eutectic Si for enhanced ductility of hypereutectic Al-20Si-4.5Cu alloy with addition of $\mathrm{Al}_{2} \mathrm{O}_{3}$ nanoparticles. J. Mater. Sci. 47 3096-3102 (2012).

15. Faraji, M., Todd, I. \& Jones, H. Effect of phosphorus and strontium additions on formation temperature and nucleation density of primary silicon in Al-19 wt Pct Si alloy and their effect on eutectic temperature

Metall. Mater. Trans. A. 40, 1710-1715 (2009).

16. Farahany, S., Idris, M. H. \& Ourdjini, A. Evaluations of antimony and strontium interaction in an Al-Si$\mathrm{Cu}-\mathrm{Zn}$ die-cast alloy. Thermochimica, 584, $72-78$ (2014).

17. Pena, B. S. \& Lozano, J. A. Microstructure and mechanical property developments in Al-12Si gravity die castings after Ti and/or Sr additions. Mater. Charact. 57 (4-5), 218-226 (2006).

18.Vijeesh, V., Ravi, M. \& Narayan Prabhu, K. The Effect of the addition of strontium and cerium modifiers on microstructure and mechanical properties of hypereutectic Al-Si (LM30) alloy. Mater. Perform. Character. 2 (1), 296-307 (2013).

19. Yan, W. et al. Evolution of solidification structures and mechanical properties of high-Si Al alloys under permanent magnetic stirring. Mater. Charact. 57 (2019).

20. Yoshikawa, T. \& Morita, K. Refining of Si by the solidification of $\mathrm{Si}-\mathrm{Al}$ melt with the electromagnetic force. ISIJ Int. 45, 967-971 (2005).

21. Jie, J. C. et al. Separation mechanism of the primary Si phase from the hypereutectic Al-Si alloy using a rotating magnetic field during solidification. Acta Mater.72, 57-66 (2014).

22. Jiang, W. et al. Segregation, and morphological evolution of Si phase during electromagnetic directional solidification of hypereutectic Al-Si alloys Materials (Basel). 12 (1) (2019).

23. Xu, C. L. et al. Cooling rate, and microstructure of rapidly solidified Al-20 wt.\% Si alloy. Mater. Sci. Eng. A, 417, 275-280 (2006).

24. Xu, C. L. \& Jiang, Q. C. Morphologies of primary silicon in hypereutectic Al-Si alloys with melt overheating temperature and cooling rate. Mater. Sci. and Eng. A, 437, 451-455 (2006).

25. Kalay, Y. E., Chumbley, L. S., Anderson, I. E. \& Napolitano, R. E. Characterization of hypereutectic AlSi powders solidified under far-from-equilibrium conditions. Met. Mat. Trans. A. 38, 1452-1457. (2007).

26. Li, X.P. et al. A selective laser melting and solution heat treatment refined Al-12Si alloy with a controllable ultrafine eutectic microstructure and 25\% tensile ductility. Acta Mater. 95, 74-82 (2015).

27. Abboud, J. H. \& Mazumder, J. Developing of nano sized fibrous eutectic silicon in hypereutectic Al-Si alloy by laser remelting. Sci. Rep. 21, 1-18 (2020).

28. Zhao, L. Z., Zhao, M. J., Song, L. J. \& Mazumder, J. Ultra-fine Al-Si hypereutectic alloy fabricated by direct metal deposition. Mater. Des. 56, 542-548 (2014).

29. Lien, H. H., Mazumder, J., Wang, J \& Misra, A. Microstructure evolution and high density of nanotwinned ultrafine Si in hypereutectic Al-Si alloy by laser surface remelting. Mater. Charact. 161, 110-147(2020). 
30. Lien, H. H. Mazumder, J. Wang, J. Misra, A. Ultrahigh strength and plasticity in laser rapid solidified AlSi nanoscale eutectics. Mater.Res. Lett. 8 (8) 291-298 (2020).

31. Wang, R. Y., Lu, W. H. \& Hogan, L. M. Faceted growth of silicon crystals in Al-Si alloys. Metall. Mater. Trans. A, 28 (5), 1233-1243. (1997).

32. Lu, S. \& Hellawell, A. Growth mechanisms of silicon in Al-Si alloys. J. Cryst. Growth. 73 (2), $316-328$ (1985).

33. Rosenthal, D. The theory of moving sources of heat and its application to metal treatments. Trans. ASME 43 (11), 849-866 (1946).

34. Eagar, I. W. \& Tsai, N.S. Temperature fields produced by traveling distributed heat sources. Welding J. 62, 346-355 (1983).

35. Grimvall, G. Thermophysical Properties of Materials.1st edition book, North-Holland, 22 September (1999).

36. Nogita, K., Drennan, J. \& Dahle, A. K. Evaluation of silicon twinning in hypo-eutectic Al-Si alloys. Mater. Trans. 44 (4), 625-628 (2003).

37. Aerts, E., Delavignette, P., Siems R. \& Amelinckx, S. Stacking fault energy in silicon. J. Appl. Phys. 33 3078 (1962). 

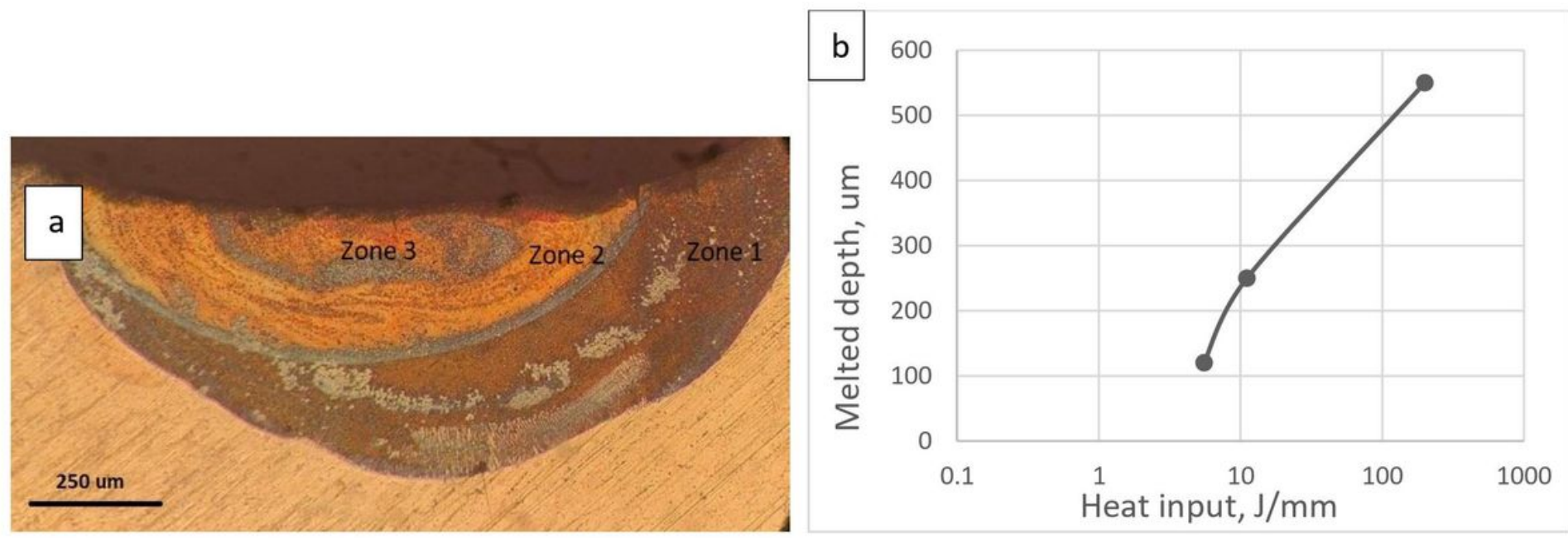

\section{Figure 1}

(a) Cross-section of the laser fabricated Al-Si alloyed layer (tracklayer 1A) and laser remelted at different heat inputs, (b) variation of the remelted depth with the heat input.
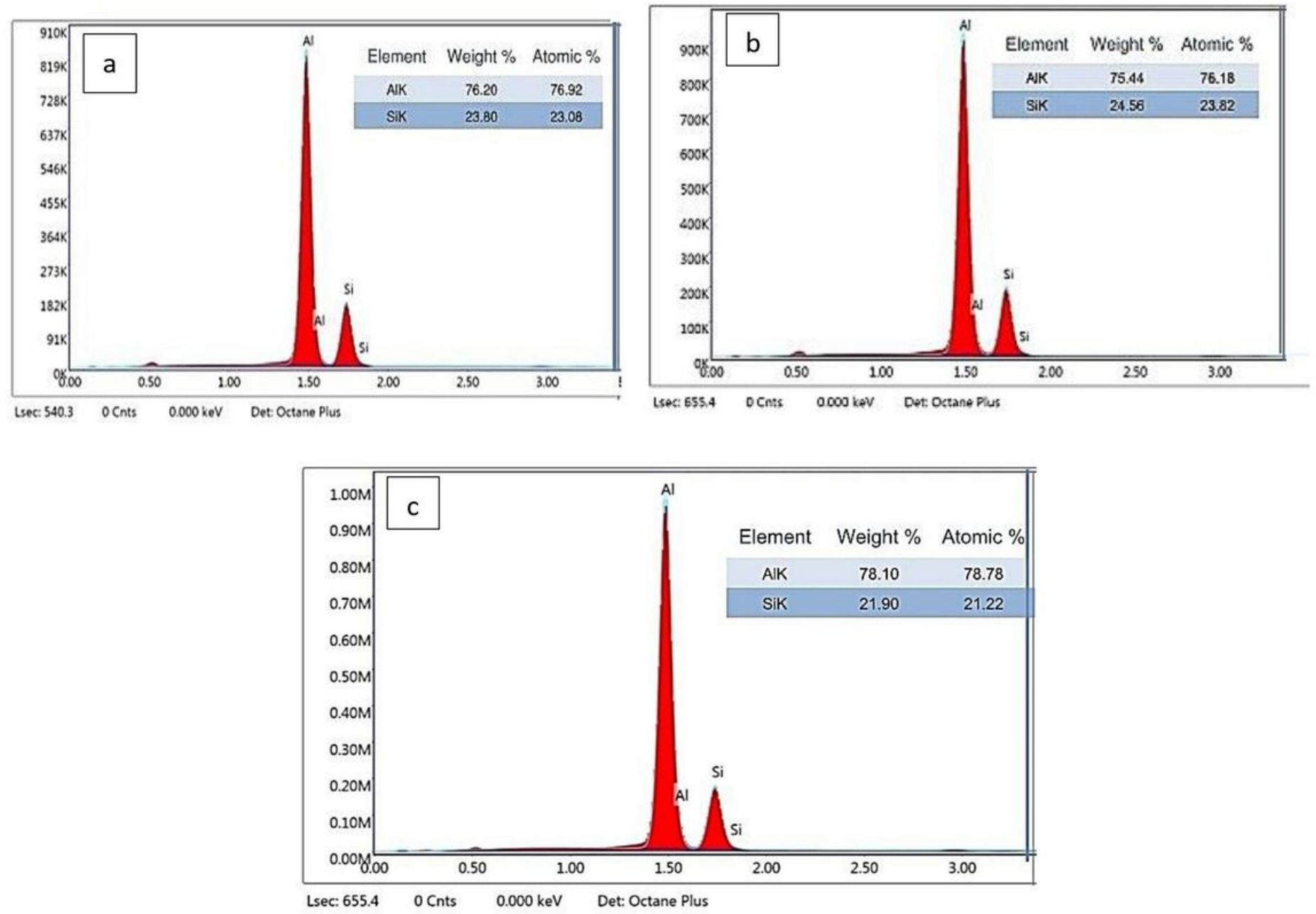
Figure 2

EDS analysis showing the composition at different locations in zone 1, (a) average composition of zone 1, (b) average composition of zone 2, (c) eutectic composition in zone 2.
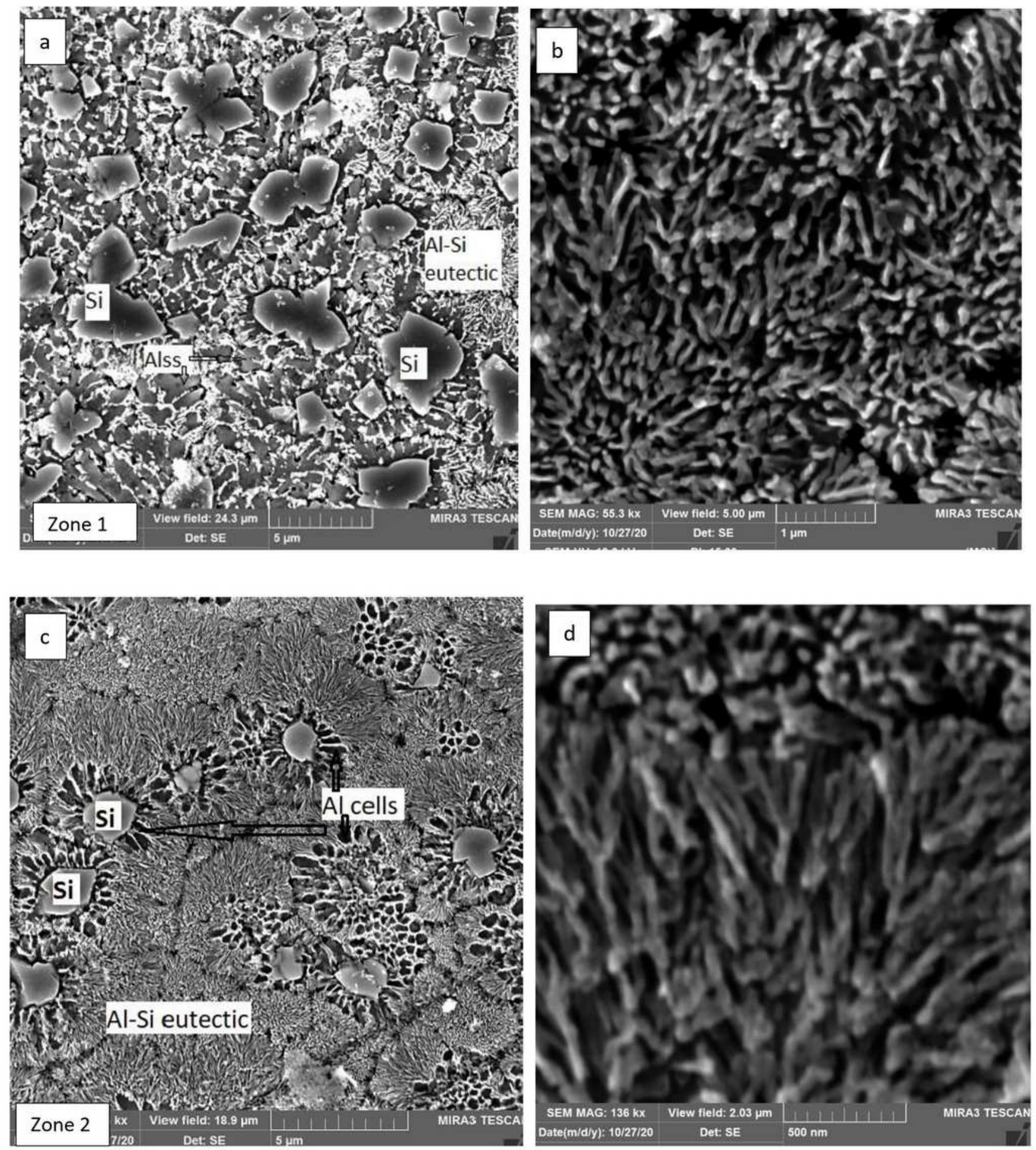

Figure 3 
SEM micrographs were taken at different locations in the laser remelted zone of Al-25wt\%Si layer showing that the primary-Si crystals coexisted with the eutectic, (a) and (b) from the lower part, zone 1 (2000W, $10 \mathrm{~mm} / \mathrm{s},(\mathrm{c})$, and (d) were taken from the upper region (zone 2), (2000W, $180 \mathrm{~mm} / \mathrm{s}$ ).
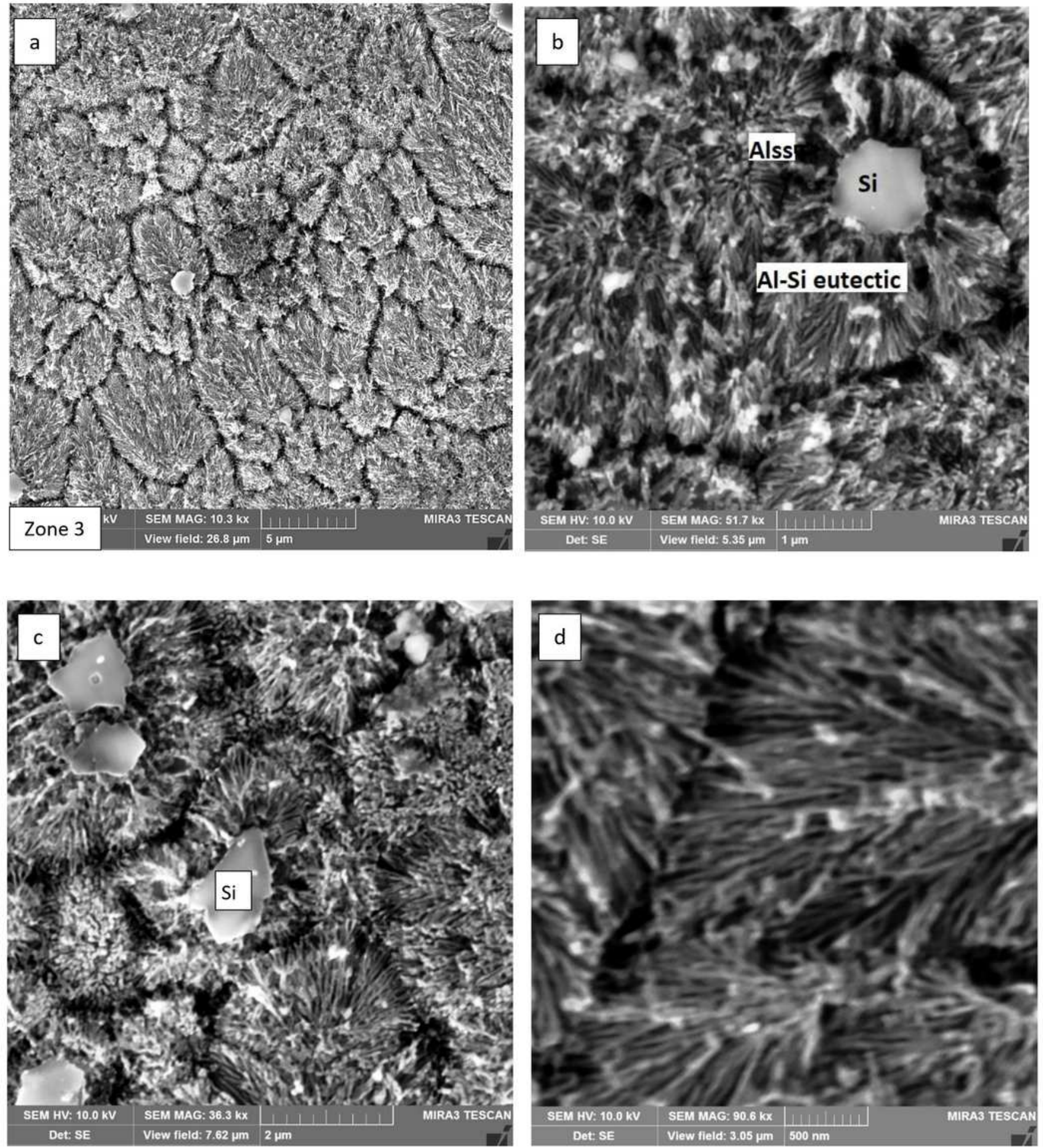

\section{Figure 4}

SEM micrographs showed the microstructure of laser remelted Al-25wt.\%Si layer at a speed of $180 \mathrm{~mm} / \mathrm{s}$ and laser power of $1000 \mathrm{~W}$ showing (a) fine eutectic colonies of size $5 \mu \mathrm{m},(\mathrm{b}-\mathrm{c})$ a-Al dendrites and fibrous 
eutectic nucleated around the primary Si, (d) fibrous eutectic.

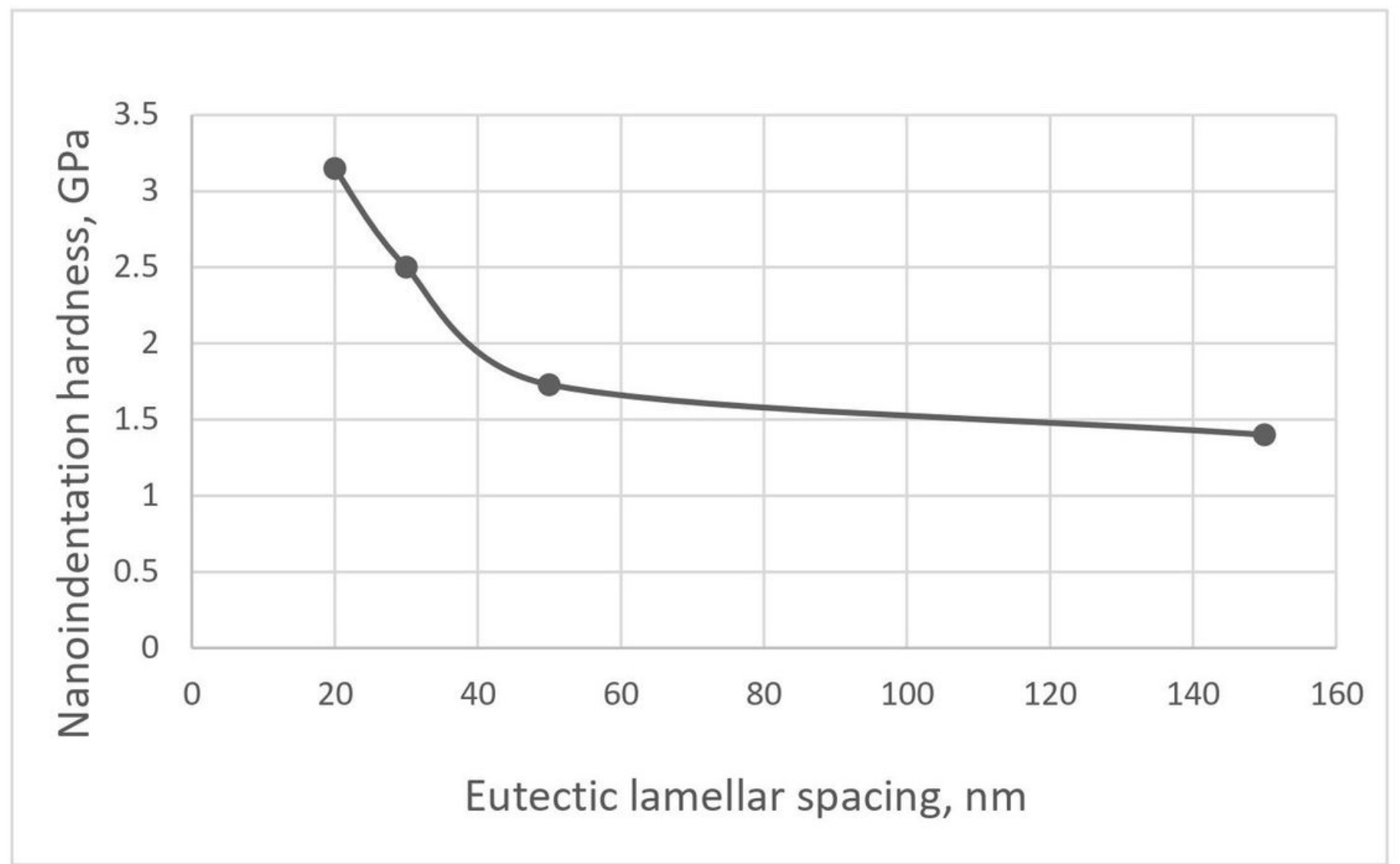

Figure 5

Nanoindentation hardness as a function of eutectic spacing, measured in different locations of the transverse section of Al-25wt.\%Si alloyed layer. 

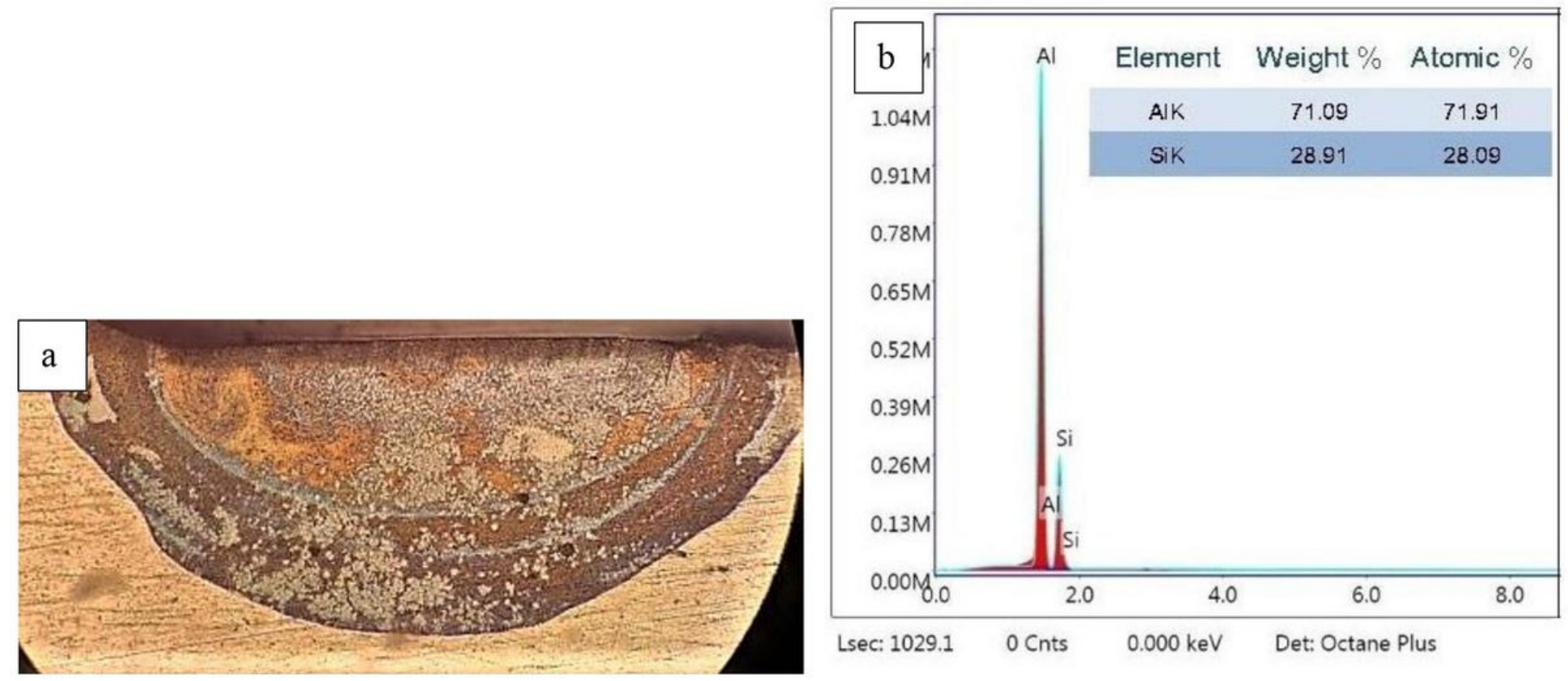

Figure 6

A cross-section of track layer (2A) fabricated at $2000 \mathrm{~W}, 10 \mathrm{~mm} / \mathrm{s}$ and remelted at $180 \mathrm{~mm} / \mathrm{s}$, (b) EDS spectrum taken from the center of zone 2 .
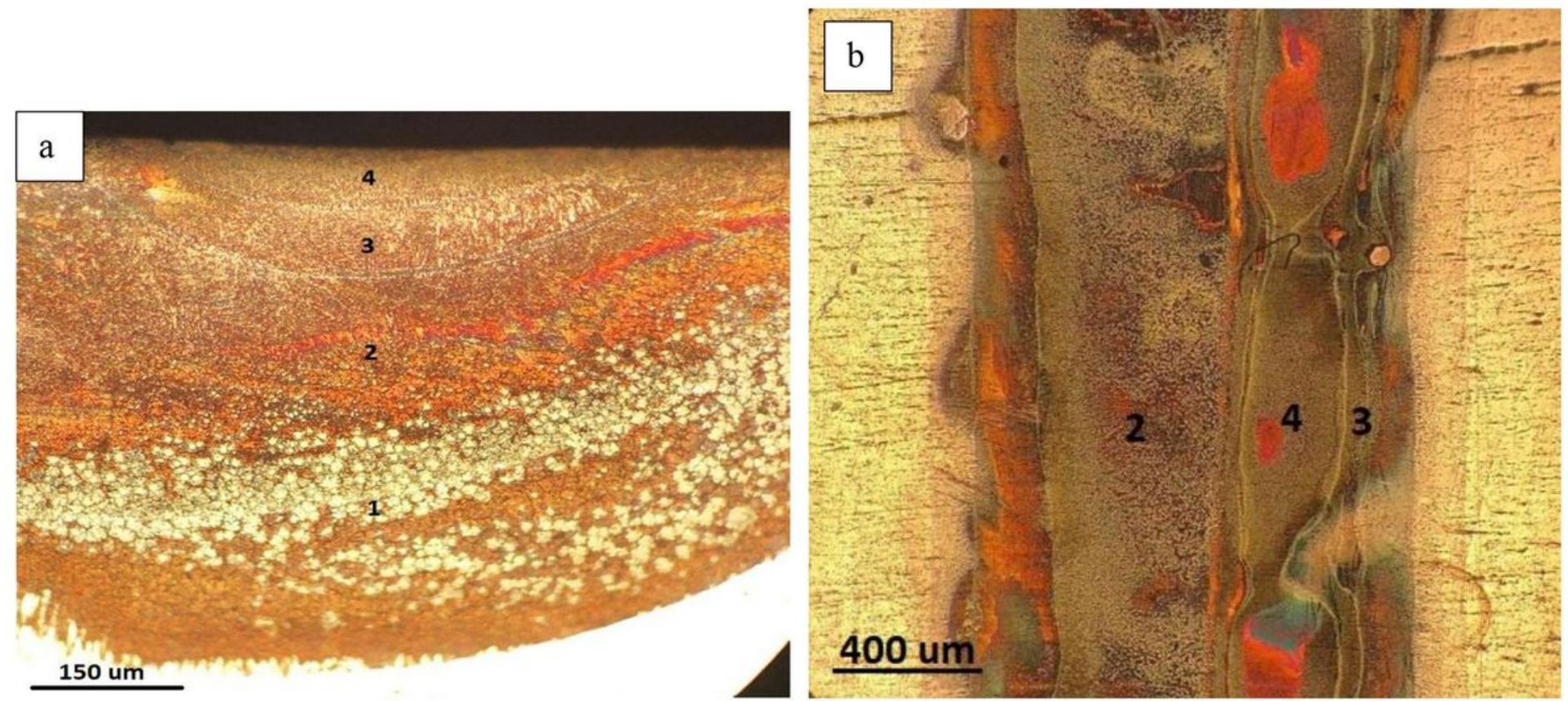

Figure 7

Optical micrograph shows a cross-section and top view of the $1 \mathrm{~A}$ track layer (Al-30wt.\%Si), which is laser remelted at different conditions, zone 2,3 , and 4 processed at powers $2000 \mathrm{~W}, 1000 \mathrm{~W}$, and $800 \mathrm{~W}$, respectively. 

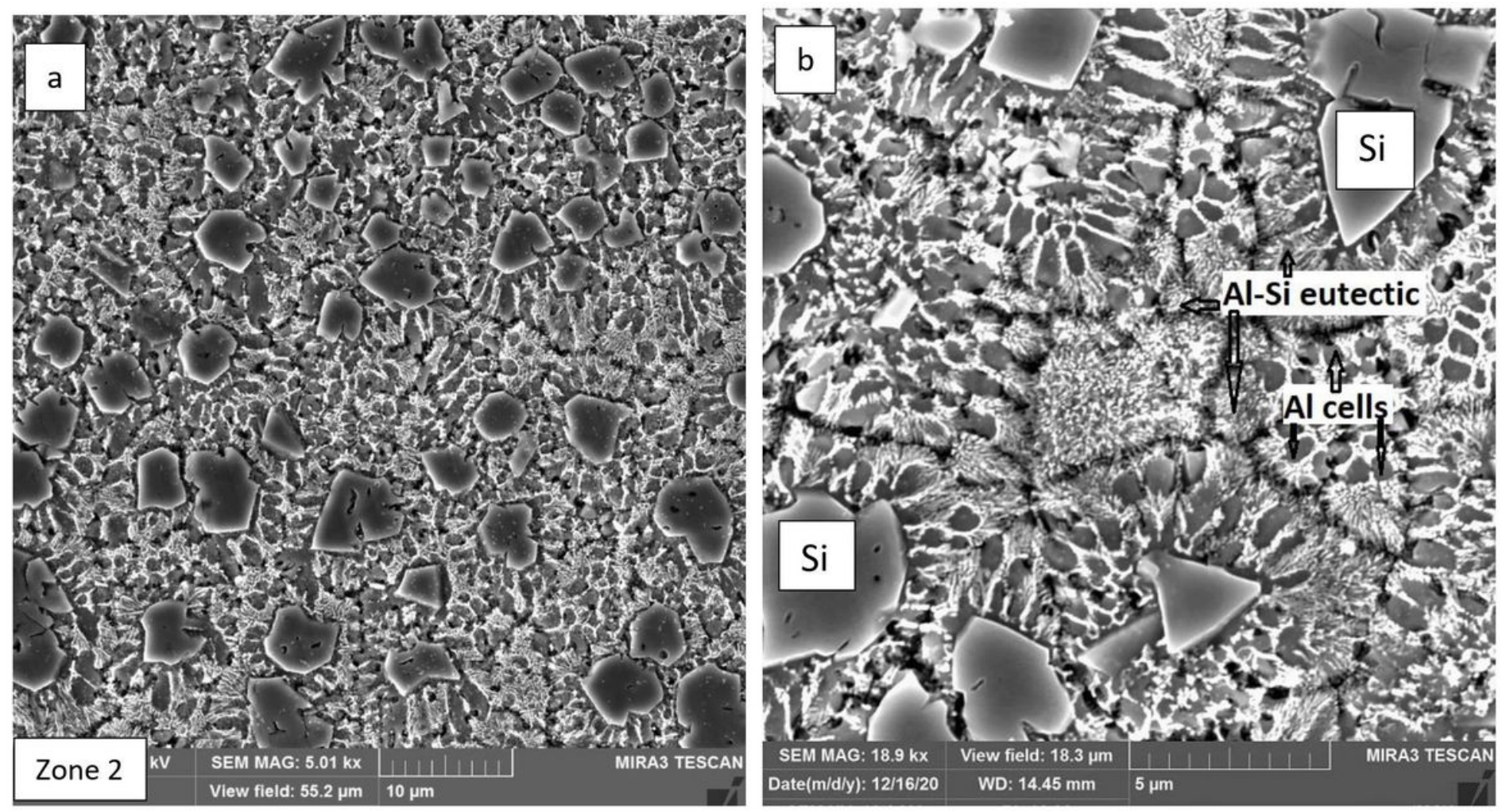

Figure 8

(a) SEM micrograph showed the microstructure Al-30wt.\%Si layer (zone 2), which was remelted 2000W and $180 \mathrm{~mm} / \mathrm{s}$. (b) Enlargement of Fig.8a illustrated primary Si, a-Al, and Al-Si eutectic.
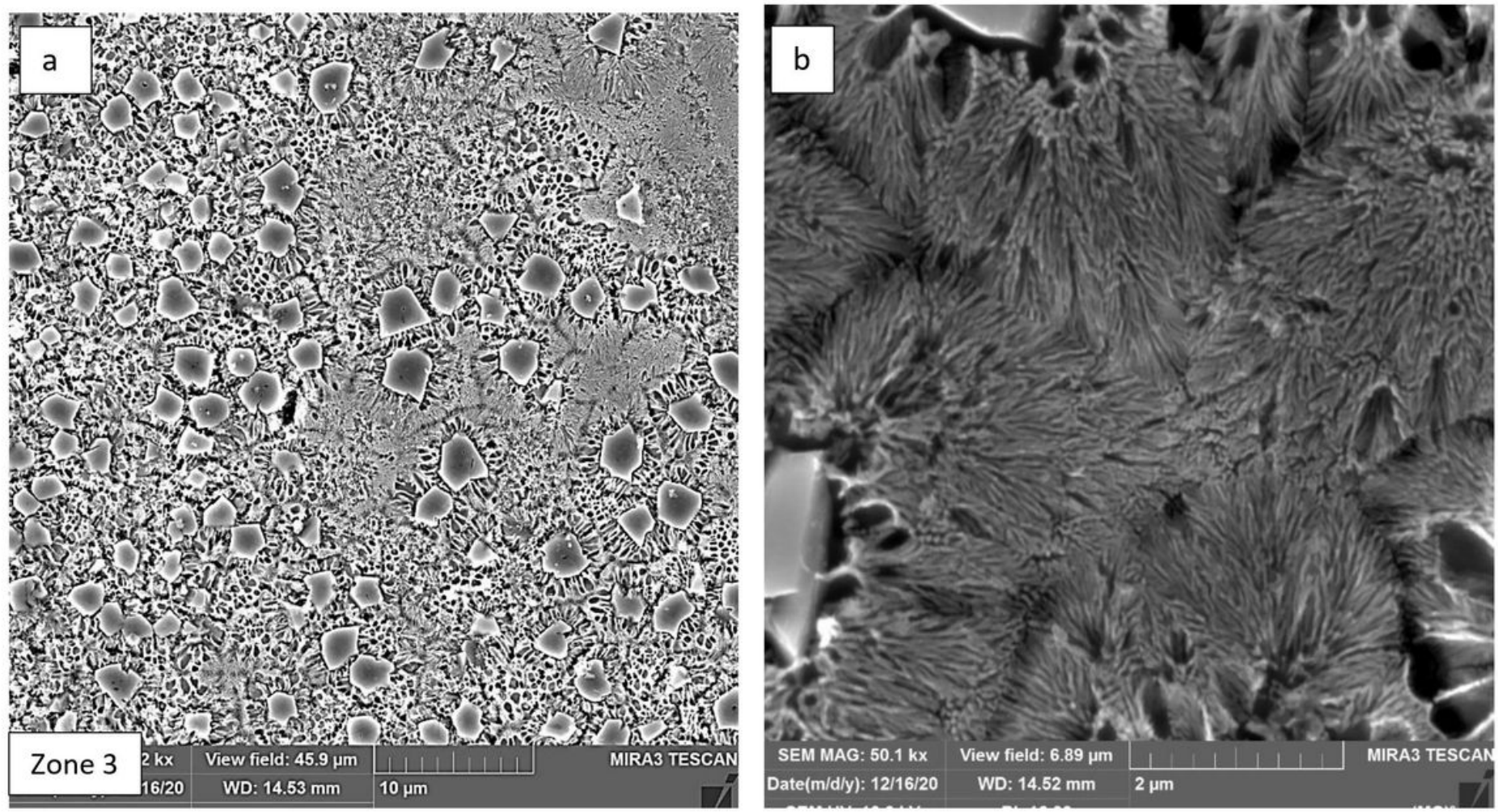

Figure 9 
(a) SEM micrograph showed the microstructure Al-30wt.\%Si layer (zone 3), which was remelted 1000W and $180 \mathrm{~mm} / \mathrm{s}$. (b) Enlargement of Fig.10a showing a high proportion of fine eutectic and PSi.
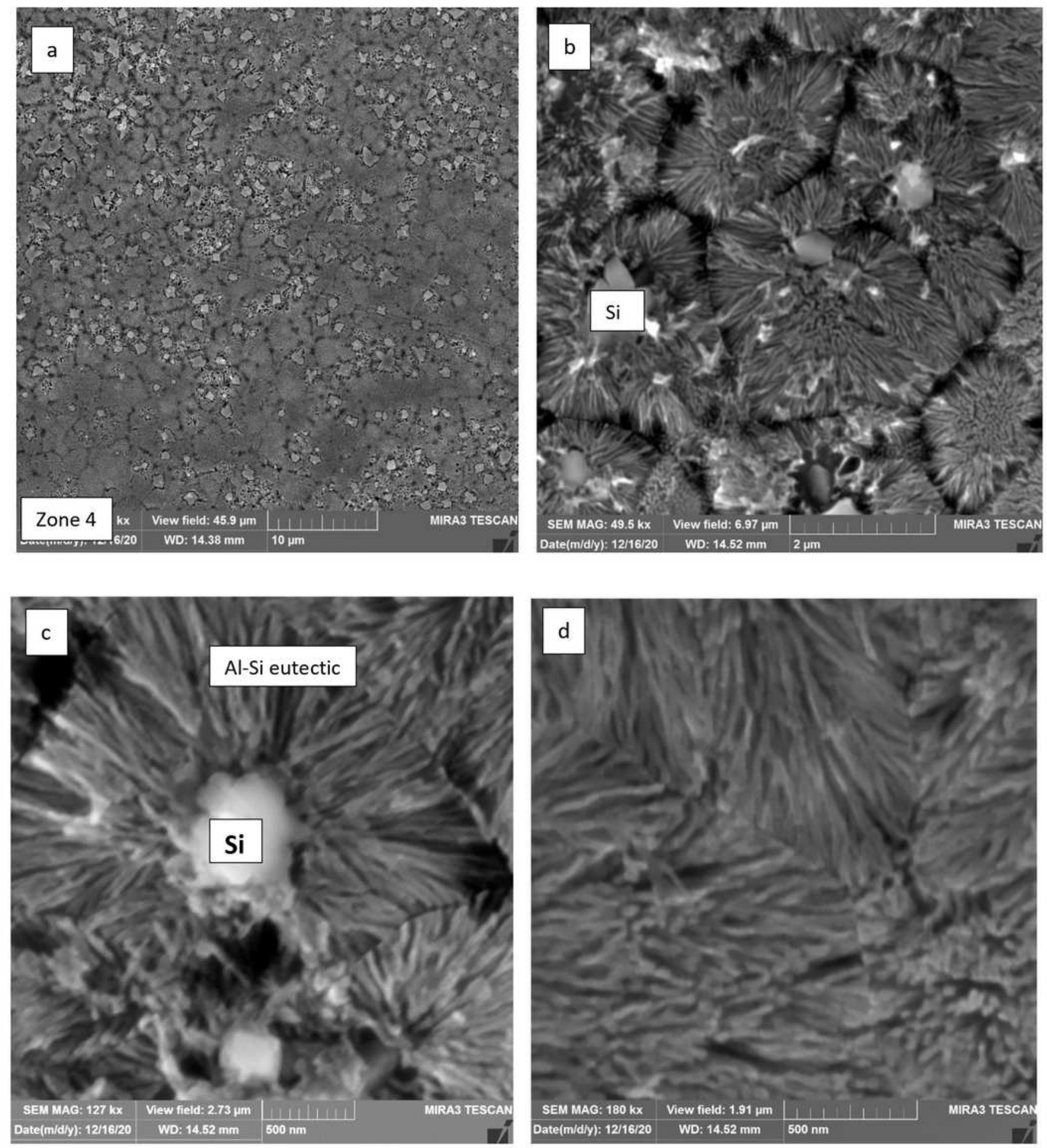

\section{Figure 10}

(a-d) SEM micrographs showed the microstructure of the Al-30wt.\%Si layer zone (zone 4), which was remelted at the lowest power $(800 \mathrm{~W})$ and fast speed $(180 \mathrm{~mm} / \mathrm{s})$ showing a modified eutectic. 

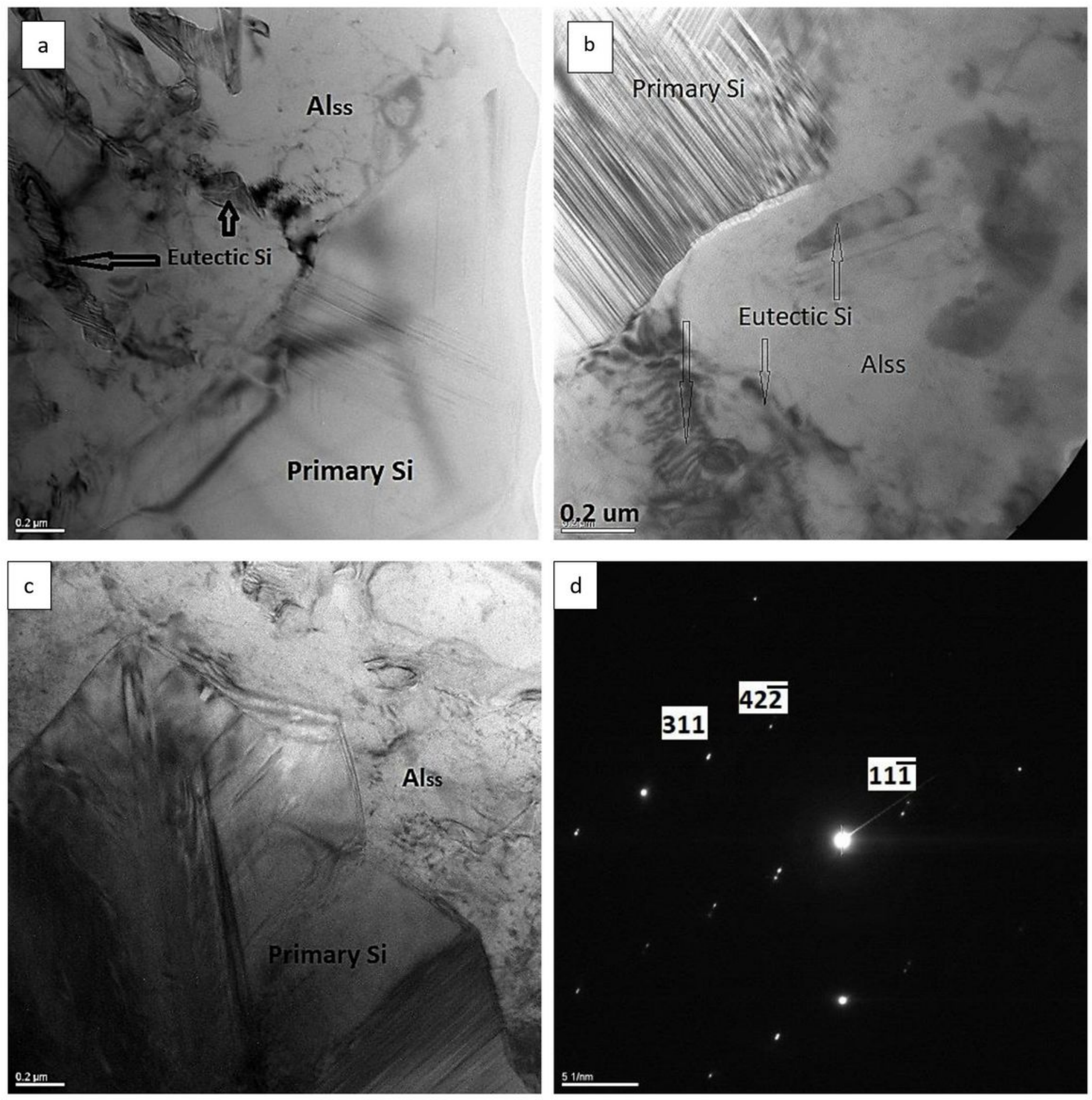

\section{Figure 11}

(a-c). TEM micrographs were taken from the least cooled Al-30wt.\%Si alloyed layer (zone 2) showing primary Si crystals contain multiple twins, eutectic $\mathrm{Si}$, and a-Al (d) SADP was taken from primary silicon, which is shown in Fig.11b, zone axis is [121]. The spot-splitting is consistent with internal twinning. 


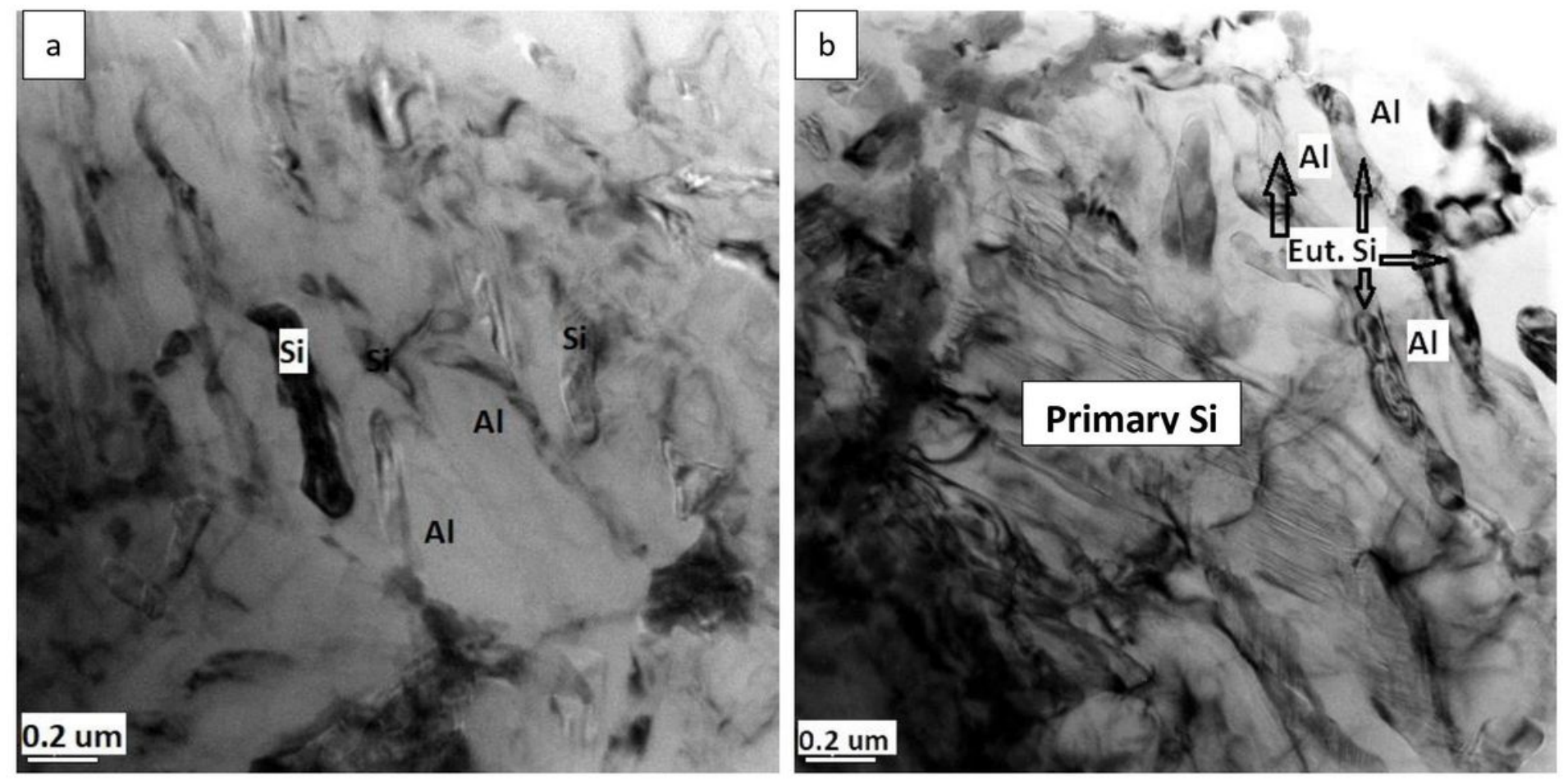

\section{Figure 12}

(a-b). TEM micrographs were taken from the Al-30wt.\%Si alloyed layer, laser remelted at a scan speed of $180 \mathrm{~mm} / \mathrm{s}$, and power 2000W (zone 2 in Fig.7) showing worm-like silicon particles of different lengths within the a-Al cells or dendrites.
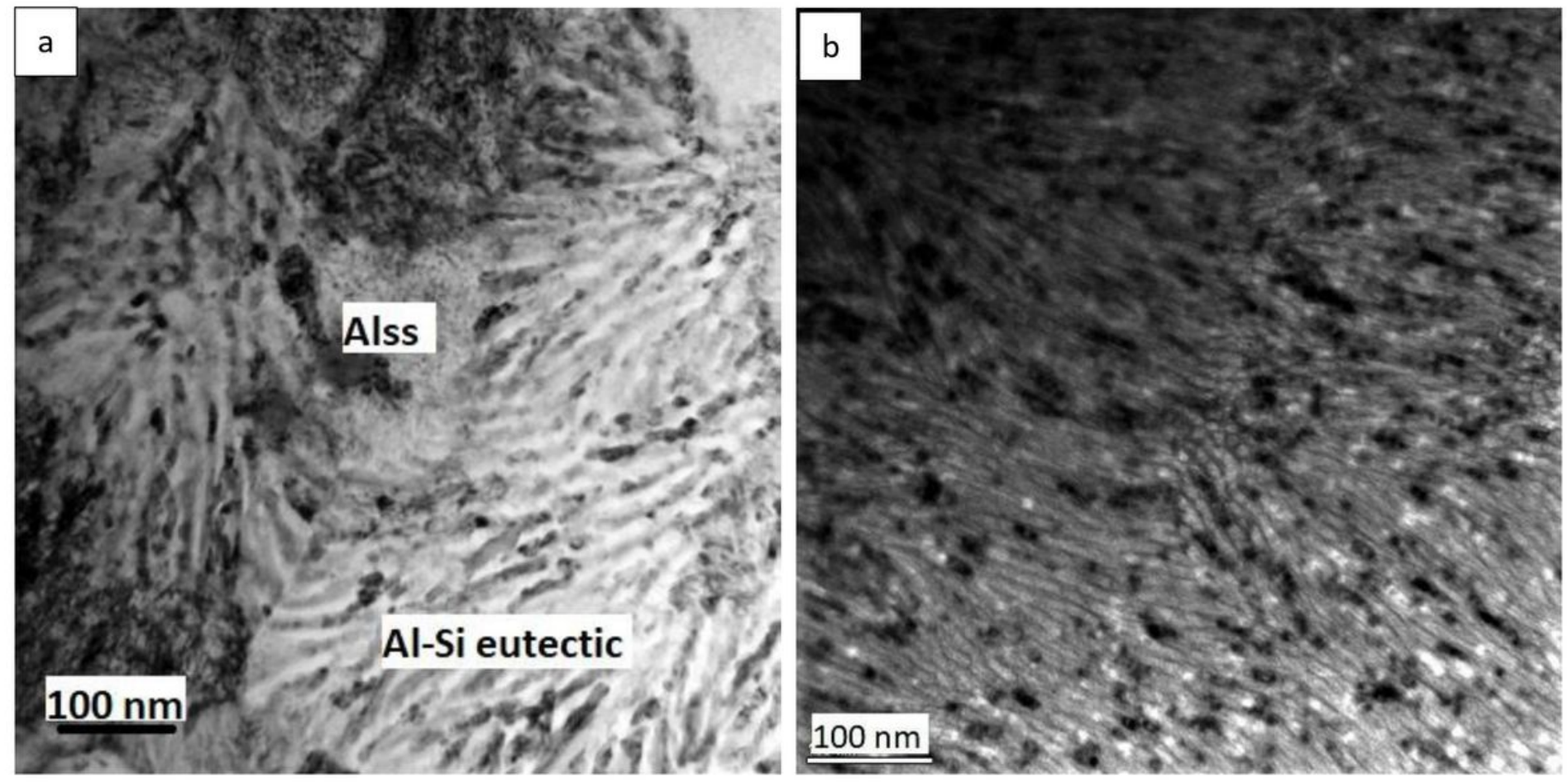

Figure 13 
(a-b).TEM micrographs show the nanosized fibrous Al-Si eutectic in Al-30wt.\%Si alloyed layer, laser remelted at a scan speed of 180 mm/s and powers (a) 1000W (zone 3, Fig.7), (b) 800W (zone 4, Fig.7). As the laser remelt power is reduced, the eutectic become much finer.
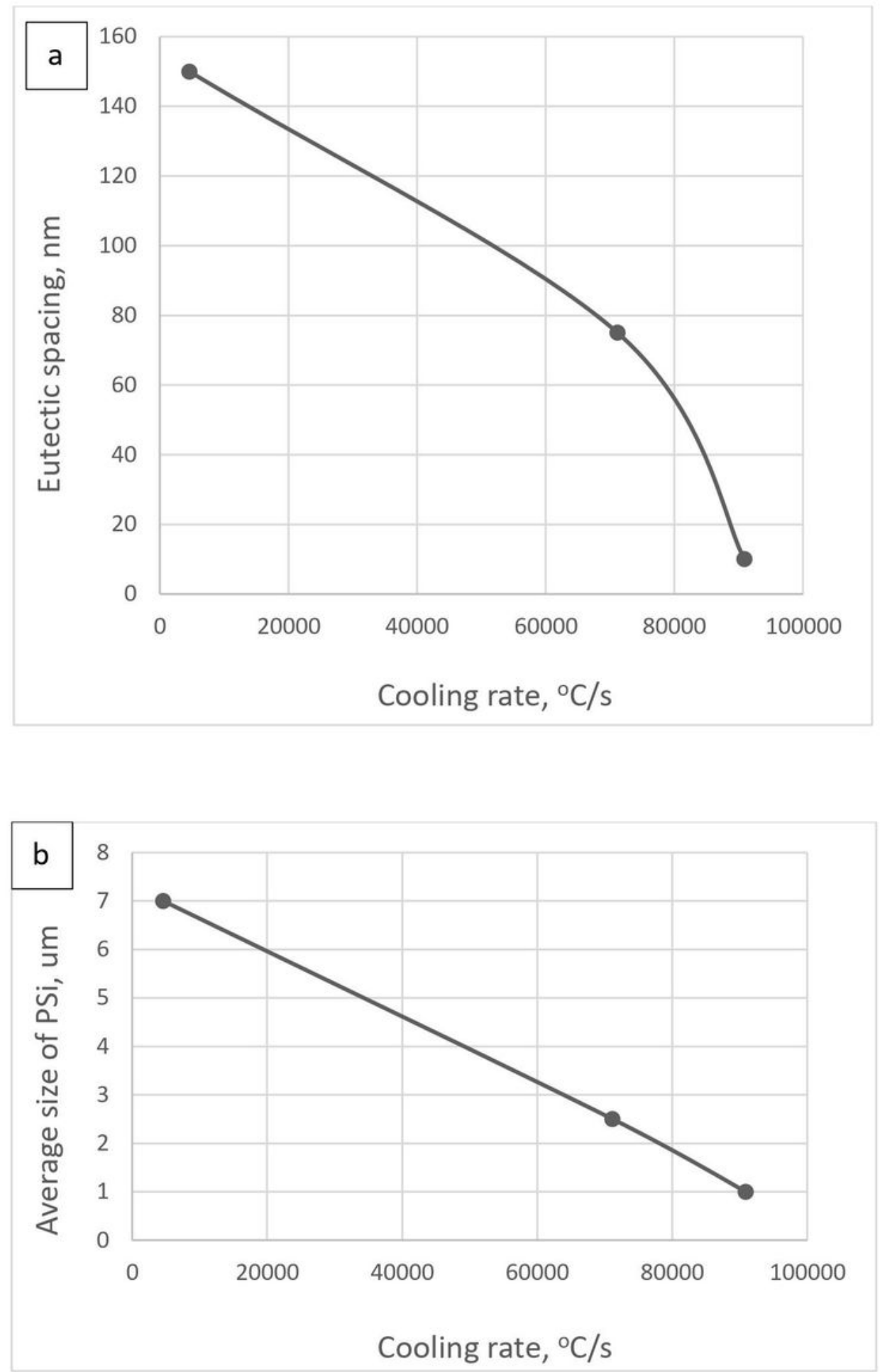

Figure 14

(a) Variation of the eutectic spacing with cooling rate, (b) variation of the primary silicon size with the cooling rate for $\mathrm{Al}-30 \mathrm{wt}$ \% Si alloyed layer laser remelted at different heat inputs. 